\title{
Whole-genome analysis of 5-hydroxymethylcytosine and 5-methylcytosine at base resolution in the human brain
}

\author{
Lu Wen ${ }^{1 \dagger}$, Xianlong $\mathrm{Li}^{1 \dagger}$, Liying Yan ${ }^{1,2 \dagger}$, Yuexi Tan ${ }^{1 \dagger}$, Rong Li ${ }^{1,2}$, Yangyu Zhao ${ }^{1,2}$, Yan Wang ${ }^{1,2}$, Jingcheng Xie ${ }^{3}$,

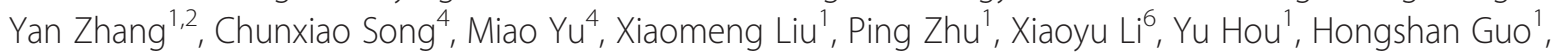 \\ Xinglong $\mathrm{Wu}^{1}$, Chuan $\mathrm{He}^{4^{*}}$, Ruiqiang $\mathrm{Li}^{1,6^{*}}$, Fuchou Tang ${ }^{1,5^{*}}$ and Jie Qiao ${ }^{1,2^{*}}$
}

\begin{abstract}
Background: 5-methylcytosine $(\mathrm{mC})$ can be oxidized by the tet methylcytosine dioxygenase (Tet) family of enzymes to 5-hydroxymethylcytosine (hmC), which is an intermediate of $\mathrm{mC}$ demethylation and may also be a stable epigenetic modification that influences chromatin structure. $\mathrm{hmC}$ is particularly abundant in mammalian brains but its function is currently unknown. A high-resolution hydroxymethylome map is required to fully understand the function of hmC in the human brain.
\end{abstract}

Results: We present genome-wide and single-base resolution maps of $\mathrm{hmC}$ and $\mathrm{mC}$ in the human brain by combined application of Tet-assisted bisulfite sequencing and bisulfite sequencing. We demonstrate that hmCs increase markedly from the fetal to the adult stage, and in the adult brain, 13\% of all CpGs are highly hydroxymethylated with strong enrichment at genic regions and distal regulatory elements. Notably, hmC peaks are identified at the 5 'splicing sites at the exon-intron boundary, suggesting a mechanistic link between $\mathrm{hmC}$ and splicing. We report a surprising transcriptioncorrelated $\mathrm{hmC}$ bias toward the sense strand and an $\mathrm{mC}$ bias toward the antisense strand of gene bodies. Furthermore, $\mathrm{hmC}$ is negatively correlated with H3K27me3-marked and H3K9me3-marked repressive genomic regions, and is more enriched at poised enhancers than active enhancers.

Conclusions: We provide single-base resolution $\mathrm{hmC}$ and $\mathrm{mC}$ maps in the human brain and our data imply novel roles of $\mathrm{hmC}$ in regulating splicing and gene expression. Hydroxymethylation is the main modification status for a large portion of CpGs situated at poised enhancers and actively transcribed regions, suggesting its roles in epigenetic tuning at these regions.

\section{Background}

Methylation of cytosine $(\mathrm{mC})$ plays a role in many crucial cellular processes. In 2009, it was shown that $\mathrm{mC}$ can be oxidized to 5 -hydroxymethylcytosine $(\mathrm{hmC})$ by tet methylcytosine dioxygenase (Tet) family of enzyme, and that embryonic stem cells (ESCs) and mouse brain tissues contain high levels of $\mathrm{hmC}[1,2]$. These and subsequent findings

\footnotetext{
*Correspondence: chuanhe@uchicago.edu; lirq@pku.edu.cn; tangfuchou@pku.edu.cn; jie.qiao@263.net

${ }^{\dagger}$ Equal contributors

${ }^{4}$ Department of Chemistry \& Institute for Biophysical Dynamics, The University of Chicago, Chicago, IL, USA

'Biodynamic Optical Imaging Center \& Center for Reproductive Medicine, College of Life Sciences, Third Hospital, Peking University, Beijing 100871, P. R. China

Full list of author information is available at the end of the article
}

evidently suggested that $\mathrm{hmC}$ is an intermediate in the long pursued pathway of active DNA demethylation [3,4].

Soon after the discovery, a series of genome-wide mapping studies of $\mathrm{hmC}$ were performed using affinity or enzyme-based approaches by us and others [5-16]. These studies, at low resolution and semi-quantitative, have provided significant insights into the distribution and functions of hmC at distal regulatory elements, gene bodies, and polycomb repression complex-bound promoters. More recently, two bisulfite-sequencing (BS-Seq) derived methods, Tet-assisted bisulfite sequencing (TAB-Seq) and oxidative bisulfite sequencing (oxBS-Seq), were established to quantitatively sequence $\mathrm{hmC}$ at base resolution $[17,18]$. The first genome-wide application of TAB-Seq to mammalian ESCs revealed novel characters of $\mathrm{hmC}$ such as its

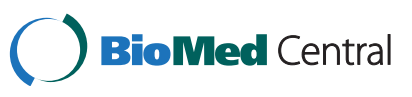


deposition around, but not within, transcription factor binding sites [17].

The content of $\mathrm{hmC}$ in the mammalian brain is typically five to ten times higher than in any other tissues, suggesting a potential role for $\mathrm{hmC}$ in the brain $[2,8,19]$. $\mathrm{hmC}$ could be an intermediate of $\mathrm{mC}$ demethylation, suggesting a potential high turnover rate of DNA methylation in the brain [20]. In addition, given its high abundance and stability, $\mathrm{hmC}$ could act as an epigenetic modification that influences genome structure and function by recruiting chromatin modifiers [21,22]. Recent studies have shown that Tet1 mutant mice exhibit memory defects, suggesting that DNA hydroxymethylation plays an important role in normal brain function $[23,24]$.

However, the exact function of $\mathrm{hmC}$ in the mammalian brain remains to be understood. Recently, Lister et al. reported comprehensive genome-wide DNA methylation maps in the human and mouse brain using BS-Seq, which also include $\mathrm{hmC}$ maps in the mouse brain using TABSeq [25]. Here, we applied TAB-Seq combined with BSSeq to map the DNA hydroxymethylome and methylome at single-base resolution in the human brain. Our data uncovered new features of $\mathrm{hmC}$ including $\mathrm{hmC}$ peaks at $5^{\prime}$ splicing sites and a transcription-corrected $\mathrm{hmC}$ bias toward the sense strand of gene bodies, implying novel roles of $\mathrm{hmC}$ in regulating splicing and gene expression in the brain.

\section{Results and discussion}

Base-resolution hydroxymethylome and methylome mapping in the human brain and identification of highly hydroxymethylated cytosines

We performed TAB-Seq and BS-Seq on a DNA sample isolated from the prefrontal cortex of an adult individual and sequenced it to an average depth of $22 \times$ per strand by TAB-Seq and $9.3 \times$ by BS-Seq. For TAB-Seq, we observed a low non-conversion rate of unmodified cytosine $(0.36 \%)$ and $\mathrm{mC}(1.18 \%)$, and a high protection rate of $\mathrm{hmC}$ (97.6\%). We also applied TAB-Seq to a DNA sample isolated from the prefrontal cortex of a fetal brain and sequenced it to an average depth of $11 \times$ per strand, with the non-conversion rates of unmodified cytosine and $\mathrm{mC}$ being $0.25 \%$ and $1.51 \%$, respectively. The sequencing details are summarized in Additional file 1. TAB-Seq detected approximately 28.4 million $\mathrm{hmCs}$ in the adult prefrontal cortex, 10-fold more than that in the fetal prefrontal cortex (approximately 2.6 million), and BS-Seq detected approximately 49.9 million modified cytosines (modCs) (false discovery rate $\leq 1 \%$; Figure $1 \mathrm{~A}$, and see Materials and methods). The much higher number of hmCs detected in the adult prefrontal cortex is consistent with previous reports $[8,9]$. To quantitatively verify this, we performed liquid chromatography-tandem mass spectrometry (LC$\mathrm{MS} / \mathrm{MS}$ ) to genomic DNAs isolated from several regions of these two brain samples, as well as another pair of fetal and adult brain samples, and the results confirmed that the abundance of $\mathrm{hmC}$ in the adult human brain is nearly six times higher than that in the fetal brain $(\% \mathrm{hmC} / \mathrm{dC}$ average 0.866 vs 0.154) (Additional files 2 and 3). Whereas a notable portion of modC exists in non-CpG contexts in the adult prefrontal cortex $(16.1 \%$ in $\mathrm{CHH}$ and $2.8 \%$ in CHG, where $\mathrm{H}=\mathrm{A}, \mathrm{C}$ or $\mathrm{T}$ ), hmC exists predominantly in CpG context (97.4\% in the adult cortex and $99.86 \%$ in the fetal cortex), which is in line with the finding in mouse [25] (Figure 1a). We also applied BS-Seq and TAB-Seq to a DNA sample extracted from the hippocampus of the fetal brain, and found that both modC and hmC exists predominantly in $\mathrm{CpG}$ context, confirming the previous finding that the non-CpG modification in the brain is adult-specific [25] (Additional file 4). Since the majority of $\mathrm{hmC}$ exists in a CpG context, we next focused our analysis on $\mathrm{CpG}$ modifications.

Examples of the $\mathrm{hmC}$ and $\mathrm{mC}$ maps were shown in Figure 1b. A genomic region of $12 \mathrm{mb}$ (mega base pairs) on chromosome 4 displays increased $\mathrm{hmC}$ levels in generich regions, coincident with a decrease in $\mathrm{mC}$ levels; these changes could not be distinguished by traditional bisulfite sequencing alone because the modC levels measured by BS-Seq change only slightly. Closer inspection of a $12 \mathrm{~kb}$ (kilo base pairs) region around the TET2 transcription start site (TSS) further supports the need for TAB-Seq. For many individual CpG sites, the $\mathrm{hmC}$ level is higher than the $\mathrm{mC}$ level. In particular, the highly modified CpGs immediately upstream the TSS are highly hydroxymethylated and could be mistaken as highly methylated sites when applying traditional BS-Seq alone. These results highlight the need to apply TAB-Seq to distinguish hmC and $\mathrm{mC}$ unequivocally for obtaining accurate hydroxymethylation and methylation maps in the brain. The hmC map of the fetal brain is also provided and suggested that patterns of hmCs in the adult brain have been partially established in the fetal stage.

We calculated the modification frequency of $\mathrm{hmC}$ and $\mathrm{mC}$ for individual $\mathrm{CpG}$ sites. In general, hmCs occur at relatively low frequency (median 29.2\% and $30.8 \%$ in the adult and fetal brains, respectively), whereas most $\mathrm{mCs}$ occur at high frequency (median 59.7\% in the adult brain) (Additional file $5 \mathrm{a}$ and $\mathrm{b}$ ). Then we classified CpG sites according to their $\mathrm{hmC}$ and $\mathrm{mC}$ frequencies. We first divided all CpGs into three categories depending on the total modification $(\mathrm{hmC}+\mathrm{mC}$, or modC). In agreement with previous studies [26], we determined that $89.8 \%$ of the CpGs are highly modified $\left(\bmod C^{\text {high }}, \bmod C \geq 50 \%\right), 6.9 \%$ are unmodified $\left(\bmod C^{\text {no }}, \bmod C<10 \%\right)$, and $3.3 \%(n=1,423,006)$ are modified at low levels $\left(\bmod C^{\text {low }}, 10 \% \leq \operatorname{modC}<50 \%\right)$ (Figure 2a). Next, we divided the $\bmod \mathrm{C}^{\text {high }}$ into three subgroups: (1) hmC $\mathrm{h}^{\text {high }}$ : $\mathrm{hmC}>\mathrm{mC}$; (2) $\mathrm{hmC}^{\text {low }}: \mathrm{hmC}<\mathrm{mC}$; and (3) $h m C^{\text {no }}$ : no hmC. We determined that $h m C^{\text {high }}$ 
(a)

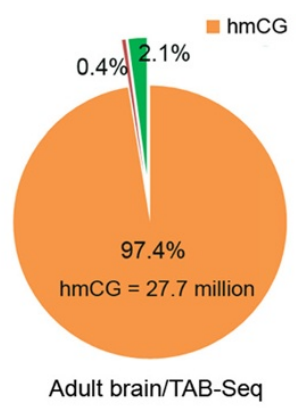

(b)

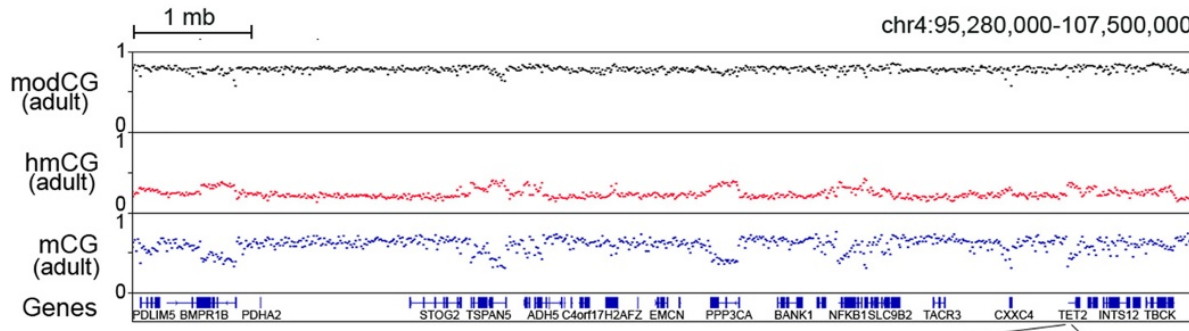

$=\operatorname{modCG}=\operatorname{modCHH}=\operatorname{modCHG}$

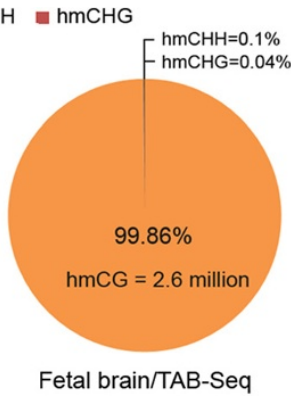

Fetal brain/TAB-Seq

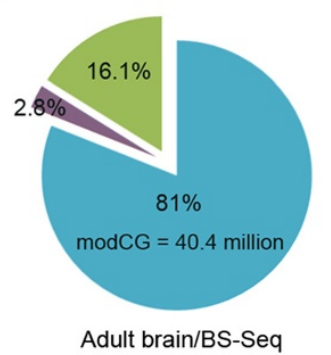

Adult brain/BS-Seq
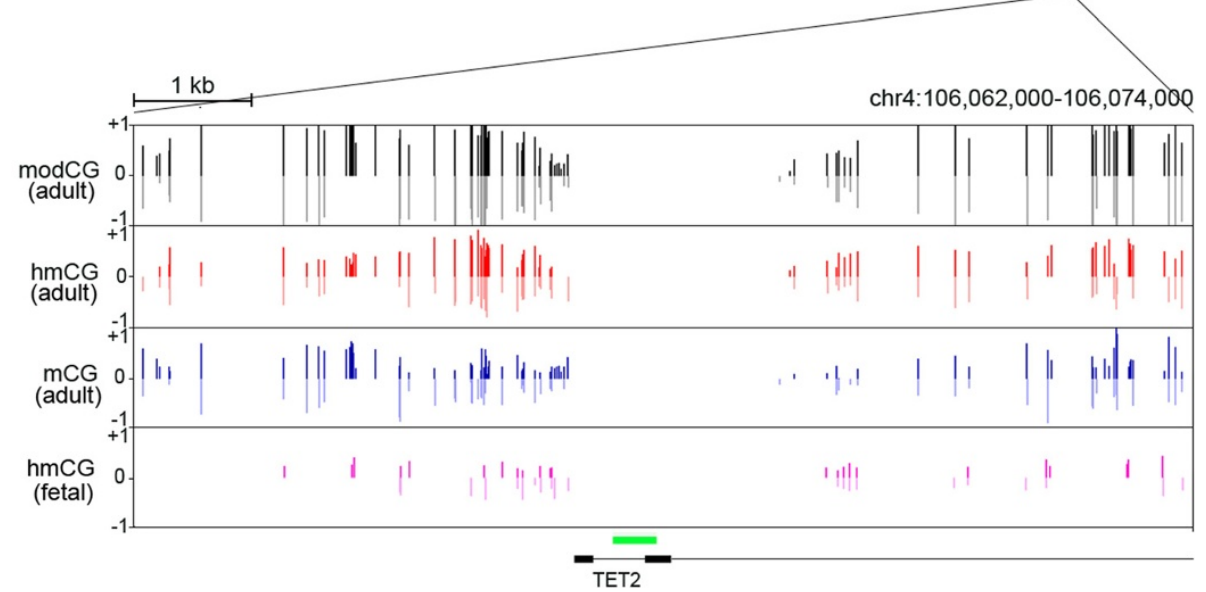

Figure 1 Base-resolution hydroxymethylome and methylome in the human brain. (a) The percentages of hmCs or modCs in the adult or the fetal brain in the contexts of $\mathrm{CG}, \mathrm{CHH}$, and CHG. (b) Examples of the $\mathrm{hmC}, \mathrm{mC}$, and total modification (hmC + mC) profiles are shown for a genomic region of $12 \mathrm{mb}$ on chromosome 4 as a scatterplot (Upper panel) and for a $12 \mathrm{~kb}$ region surrounding the TSS of the TET2 gene as a bar chart. The green box indicates the CpG island located in the TET2 promoter.

$(n=5,692,354)$ accounts for a notable proportion $(13.4 \%)$ of all captured CpGs. The hmC $\mathrm{C}^{\text {low }}(n=20,857,810)$ and $\mathrm{hmC}^{\mathrm{no}}(n=11,695,002)$ categories comprised $49 \%$ and $27.4 \%$, respectively. Since further analysis revealed that $\mathrm{hmC}^{\text {low }}$ and $\mathrm{hmC}^{\text {no }}$ have similar characters, they were grouped into $\mathrm{mC}^{\text {high }}$ referring to highly-methylated cytosines (Figure 2a).

\section{Genomic distribution of $\mathrm{hmC}$ in the human brain}

Next, we determined the genomic distribution of $\bmod C^{\text {low }}$, $\mathrm{hmC} \mathrm{C}^{\text {high }}$, and $\mathrm{mC}^{\text {high }}$. In addition to the annotated genomic features, we also analyzed enhancers mapped by a recently published ChIP-Seq dataset in the human brain [27]. Two types of enhancers were distinguished: active enhancers that were simultaneously marked by distal H3K4me1 and
H3K27ac, and poised enhancers that were solely marked by distal H3K4me1 [28]. modC ${ }^{\text {low }}$ is prominently enriched at enhancers (Figure $2 \mathrm{~b}$ ), which is in accordance with previous bisulfite studies [26]. We found that $\mathrm{hmC} \mathrm{h}^{\text {high }}$ is also highly enriched at enhancers. In contrast to more enrichment of modClow at active enhancers, $h m C^{\text {high }}$ is more enriched at poised enhancers (Figure 2b). Furthermore, $\mathrm{hmC}^{\text {high }}$ is abundant at introns and exons. Most $\mathrm{hmC} \mathrm{C}^{\text {high }}$ (56.9\%) occur at genic regions (Additional file 5c), and this is distinct from $\mathrm{hmC}$ distribution in ESCs [17]. By contrast, $\mathrm{mC}^{\text {high }}$ are not enriched at enhancers or genic regions. We calculated the $\mathrm{hmC}$ and $\mathrm{mC}$ levels of these genomic elements (Figure 2c). We observed that poised enhancers have the highest hmC level (32.6\% on average), followed by active enhancers $(28.6 \%)$, introns $(27.8 \%)$, exons $(27.7 \%)$, 


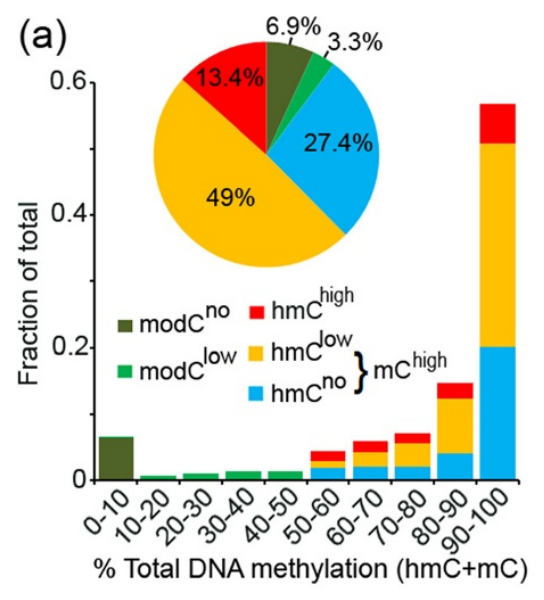

(c)

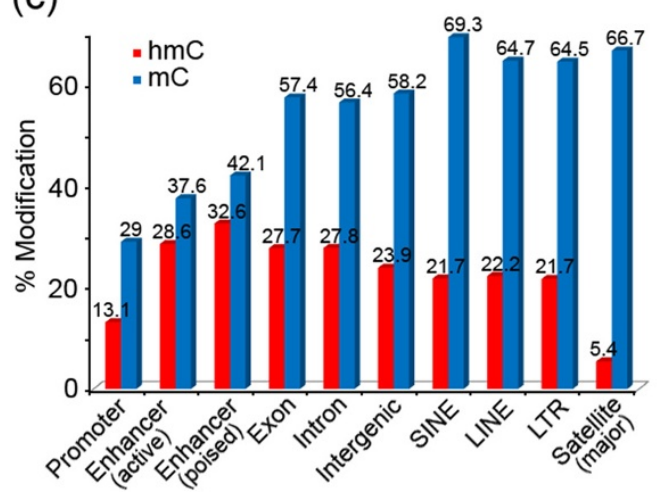

(b)

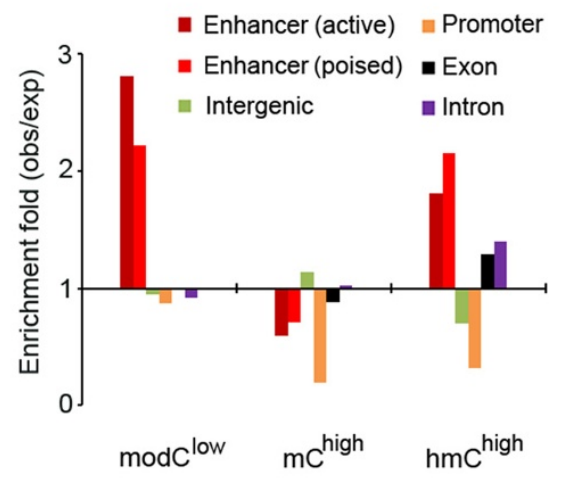

(d)

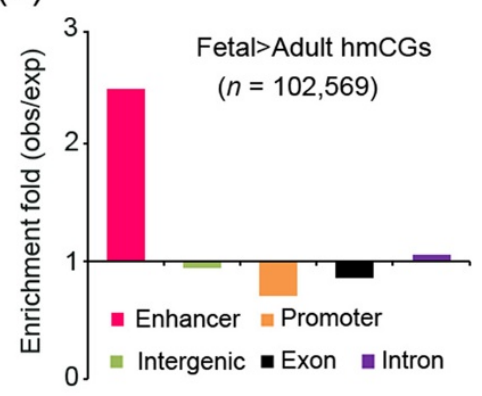

Figure 2 Features of hydroxymethylome in the human brain. (a) Classification of all CpGs in the adult brain according to their hydroxymethylation and methylation frequencies. (b) Fold enrichment of the CpG categories on different genomic elements. hmChigh is enriched in enhancers, exons and introns. (c) The absolute $\mathrm{hmC}$ and $\mathrm{mC}$ levels at different genomic elements in the adult brain. (d) Fold enrichment of the Fetal > Adult hmCGs, which exhibited higher hmC levels in the fetal brain than in the adult brain, on different genomic elements.

and intergenic regions (23.6\%). The $\mathrm{mC}$ levels follow the reverse order, with the intergenic regions $(58.2 \%)$ being highest, followed by exons (57.4\%), introns (56.4\%), and enhancers $(42.1 \%$ and $37.6 \%$ for poised and active enhancers, respectively). The promoter regions have both the lowest $\mathrm{hmC}$ and $\mathrm{mC}$ levels. Repetitive sequences, including LINE, SINE, LTR, and major satellite repeats, generally have lower $\mathrm{hmC}$ and higher $\mathrm{mC}$ levels than the non-repetitive regions, and the major satellite repeats have the lowest hmC level (5.4\%).

We determined that the hmC levels of the fetal brain are much lower than those of the adult brain in all genomic regions (Additional file 5d). Despite this, we identified 102,569 CpGs that exhibited higher hmC levels in the fetal brain than in the adult brain (both coverage $\geq 10$, methylation difference $\geq 0.3$ ). Analysis for the genomic distribution of these Fetal > Adult hmCGs showed that they are highly enriched at enhancers, but not at other genomic features (Figure 2d). The result suggested that $\mathrm{hmC}$ changes at enhancers are bidirectional with a subset of enhancers gaining and some losing hydroxymethylation from the fetal to the adult stage, which is consistent with the previous report that $\mathrm{hmC}$ marks regulatory elements in the fetal brain that is poised for subsequent activation in the adult brain [25].

\section{Prominent $\mathrm{hmC}$ peaks mark the exon-intron boundary}

Despite previous suggestions that $\mathrm{hmC}$ may be associated with the exon-intron boundary in the brain [14], the low-resolution method employed previously prevented accurate analysis at the base resolution. Conversely, whole-genome BS-Seq studies have shown that DNA modification is abundant on exons [29-31]. These studies, however, were not able to distinguish between $\mathrm{mC}$ and $\mathrm{hmC}$. One intriguing finding of our analyses of the base-resolution $\mathrm{hmC}$ and $\mathrm{mC}$ maps is two striking hmC peaks at the $5^{\prime}$ splicing sites ( 5 'ss), which are positioned flanking the highly conserved 'GT' sequence, with a higher peak siting at positions -1 and -2 on the exon side and a lower one at positions +4 and +5 on the intron side (all internal exons, $n=176,455$ ) (Figure $3 \mathrm{a}$ and Additional file 6). In contrast, $\mathrm{mC}$ is not enriched. Notably, analysis 

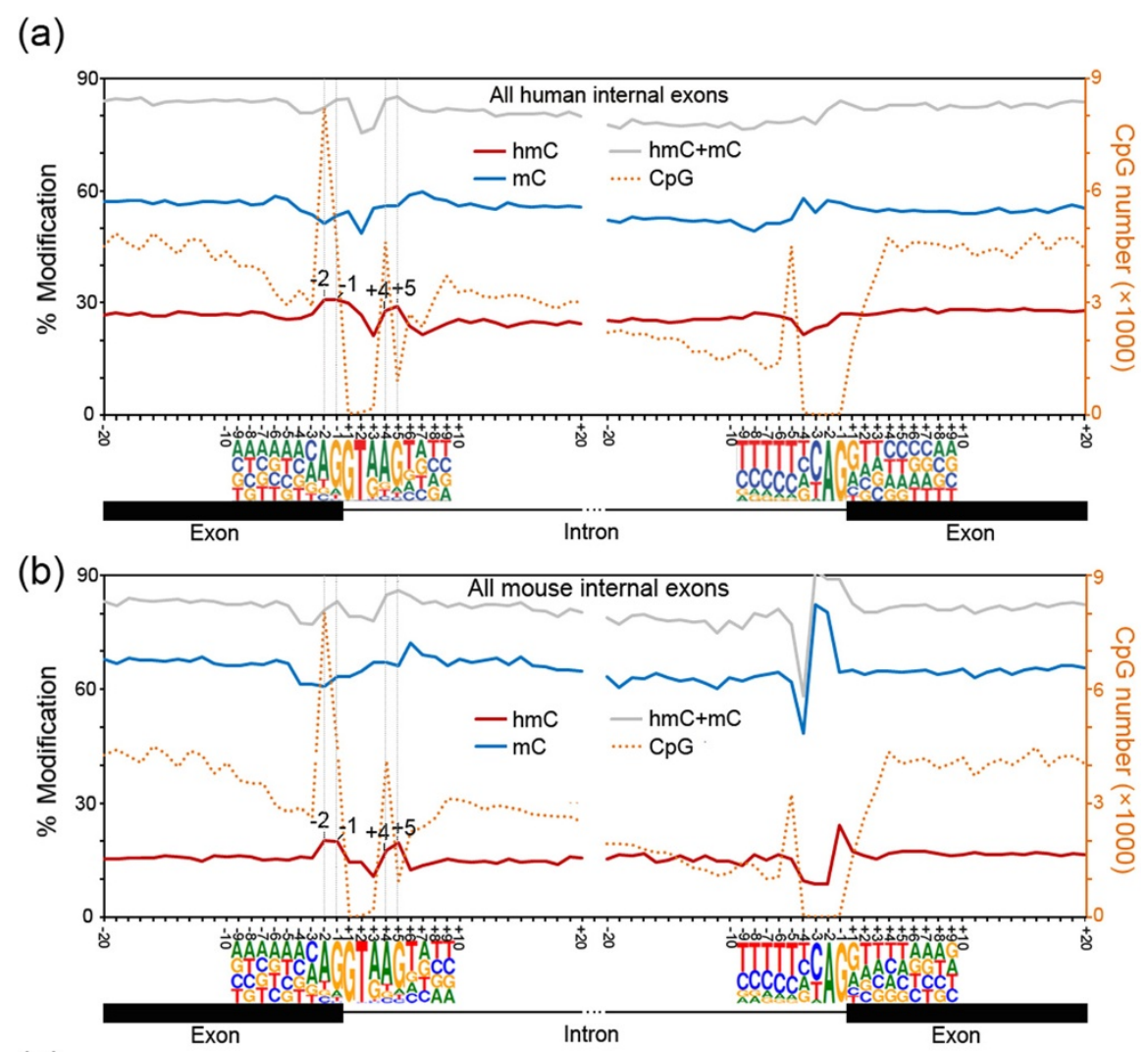

(c)
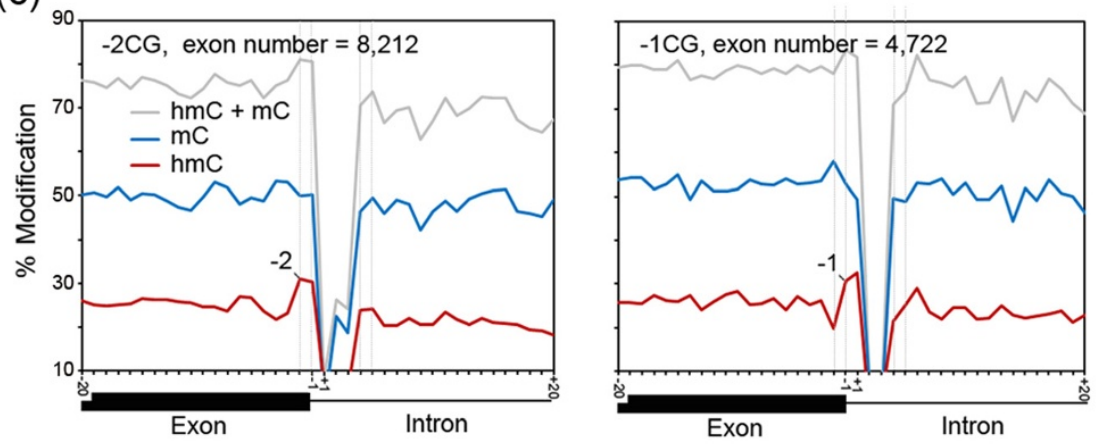

(d)

(e)
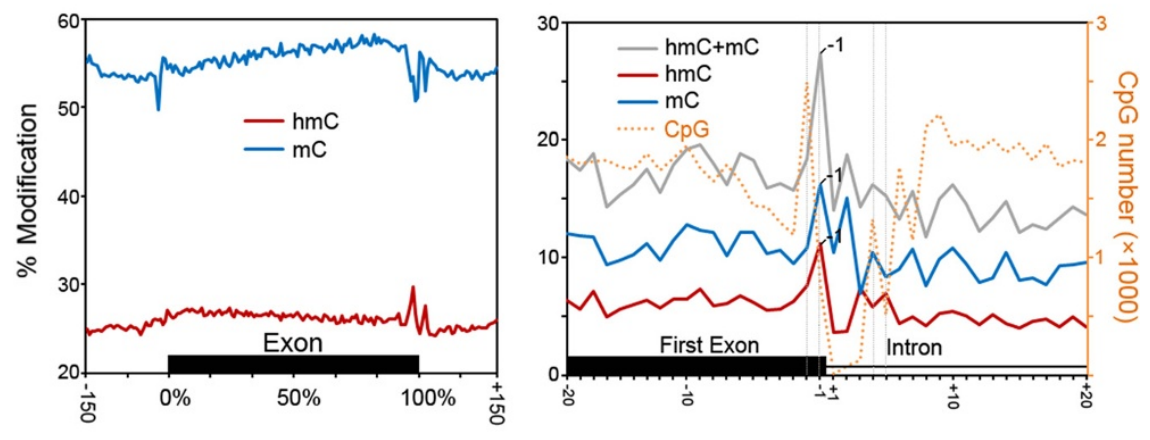

Distance from region (bp or \%)

Figure $\mathbf{3}$ (See legend on next page.) 
(See figure on previous page.)

Figure 3 Prominent hmC changes mark the exon-intron boundary. $(\mathbf{a}, \mathbf{b})$ Profiles of $\mathrm{hmC}$ and $\mathrm{mC}$ for a 40-bp window around the exon-intron and intron-exon boundaries at single-nucleotide resolution in human (a) and mouse (b). Modification levels of hmC, mC, total DNA methylation (hmC + hmC), and the CpG number are shown for all internal exons in the sense strand. The sequences \pm 9 bp around the $5^{\prime}$ and $3^{\prime}$ splicing sites are also indicated. The TAB-Seq and BS-Seq data to generate the mouse profile (b) were obtained from Lister et al. [25]. (c) Profiles of hmC and $\mathrm{mC}$ at the exon-intron boundary of exons which have a CpG at 5'ss position -2 $(-2 \mathrm{CG}, n=8,212)$ or $-1(-1 \mathrm{CG}, n=4,277)$. Since a $\mathrm{CpG}$ at one position will lead to absence of $\mathrm{CpG}$ at the nearest neighboring position and thus no methylation value, we merged the data of the sense and the antisense strands for each type of exons. (d) Profiles of hmC and $\mathrm{mC}$ across exons. All internal exons were divided into $100 \mathrm{bins}$, and average $\mathrm{hmC}$ and $\mathrm{mC}$ levels were calculated for each bin, as well as $\pm 150 \mathrm{bp}$ surrounding the exon. (e) The $\mathrm{hmC}$ and $\mathrm{mC}$ profiles at the exon-intron boundary of the first exon.

of the recently published TAB-Seq (GSM1173795) and BS-Seq (GSM1173783) data generated from the adult mouse brain tissue (frontal cortex from 6-week-old male mouse brain) [25] revealed two nearly identical hmC peaks at the 5 'ss, indicating that this pattern is conserved in mammals (Figure $3 \mathrm{~b}$ ). The CpGs at both peaks are not part of the consensus 5 'ss sequence (CAG/GTAAGT). However, the peak positions -2 and +4 have higher tendencies to be CpG sites than the overall exons and introns (Figure $3 \mathrm{a}$ and $\mathrm{b}$ ). The profile of $\mathrm{CpG}$ distribution has been recently reported [32]. We further determined that, of the 176,455 examined human exons, 12,934 (7.3\%, 4722 at position -1 and 8,212 at position -2) have CpG sites at positions related to the exon-side peak and 5,514 (3.1\%, 4605 at position +4 and 909 at position +5 ) have CpG sites related to the intron-side peak (Figure 3a). Overall, these exons $(n=18,036,10.2 \%$ of all 176,455 human internal exons) represent a large proportion of human genes $(n=$ 9,103, 48.9\% of all 18,606 human genes, see Additional file 7 for 5 'ss sequences of these exons and the corresponding genes). To exclude the possibility that the $\mathrm{hmC}$ peaks are artifacts due to higher $\mathrm{hmC}$ levels of the exons which have a CpG site at the 5'ss than those do not have, we separately analyzed the exons which have a CpG site at the 5 'ss position $-2,-1,+4$ or +5 , and the results are similar to that for all internal exons (Figure $3 \mathrm{c}$ and Additional file 8). These results together indicated that prominent $\mathrm{hmC}$ peaks mark the 5 'ss at the exon-intron boundary in both human and mouse, and are associated with a large cohort of internal exons.

A decrease in $\mathrm{hmC}$ at positions +6 and +7 directly following the intron-side hmC peak was also observed for all internal exons (Figure 3a and Additional file 5: Figure S4), which seems to be similar to the intronic hmC decrease reported previously [14]. In addition to these $\mathrm{hmC}$ changes at the $5^{\prime}$ ss, we also observed a marked increase in $\mathrm{mC}$ and a less pronounced decrease in $\mathrm{hmC}$ from $5^{\prime}$ to $3^{\prime}$ across the exons (Figure 3c). We also examined the first exons $(n=12,980)$, and found that they have higher CpG occurrence and much lower $\mathrm{hmC}$ and $\mathrm{mC}$ levels than the internal exons (Figure 3d), which should be due to their proximity to promoter $\mathrm{CpG}$ islands. Interestingly, in contrast to the internal exons, $\mathrm{mC}$ is strongly enriched, and $\mathrm{hmC}$ change follows the $\mathrm{mC}$ change. The distinction between the internal exons and the first exons is suggestive of a functional connection between the $\mathrm{hmC}$ peaks and alternative exon inclusion, which should only occur in the internal exons.

To determine whether the observed $\mathrm{hmC}$ and $\mathrm{mC}$ changes are associated with gene expression, we generated RNA-Seq data using RNA extracted from the same adult brain sample for TAB-Seq and BS-Seq and divided the expressed genes (RPKM $>0.1)$ into three groups of identical size of high, middle and low expression levels (Additional file 9). The genes within these three groups, as well as genes not expressed, displayed similar $\mathrm{hmC}$ changes around their exon-intron boundary. This was unlike overall $\mathrm{hmC}$ levels within both exons and introns, which positively correlates to gene expression levels (Figure 4a). In addition, the $\mathrm{hmC}$ decrease and the $\mathrm{mC}$ increase across the exon are also similar among genes transcribed at different levels (Figure $4 \mathrm{~b}$ ). These results suggested that the $\mathrm{hmC}$ and $\mathrm{mC}$ changes occur irrespective of the transcription levels of the corresponding genes.

Next, we address the potential functional relationship between the DNA modification at the exon-intron boundary and the splicing. We classified the exons having a CpG site at the 5 'ss position $-2,-1,+4$ or +5 into four types according to the DNA modification states of the CpG site (that is, $\mathrm{mC}^{\text {high }}, \mathrm{hmC}^{\text {high }}$, $\operatorname{modC^{\text {low}}}$, or $\operatorname{modC} \mathrm{C}^{\text {no }}$ ) and compared their inclusion rates (see Materials and methods). We also examined the number of the alternatively spliced (AS) exon, which was defined as the inclusion rate being less than 0.8. The results demonstrated that the $\mathrm{hmC}^{\text {high }}$ and $\mathrm{mC}^{\text {high }}$ exons comprised a similar fraction of AS exons (6.04\% (128 out of 2,119 exons) vs. $5.63 \%$ (367 out of 6,522 exons), Figure 4c), with the inclusion rates being no difference (median 0.9901 vs. $0.9908, P=0.13$, twotailed Mann-Whitney-Wilcoxon (MWW) test, Figure 4d). Also no difference was found comparing the $\mathrm{hmC}^{\text {high }}$ and $\mathrm{mC}^{\text {high }}$ exons with the internal exons put together (median inclusion rate $0.9912, P>0.1$, AS exons percent: $6.76 \%$ (6,929 out of 102,474 exons)). These results suggested that $\mathrm{hmC}$ and $\mathrm{mC}$ at the 5 'ss CpG site are similarly related to splicing. Interestingly, the $\bmod C^{\text {low }}$ and $\bmod C^{\text {no }}$ groups involved markedly more AS exons (9.67\% (59 out of 610 exons) and $18.76 \%$ (103 out of 549 exons), respectively, Figure 4c). In addition, the inclusion rates of the 

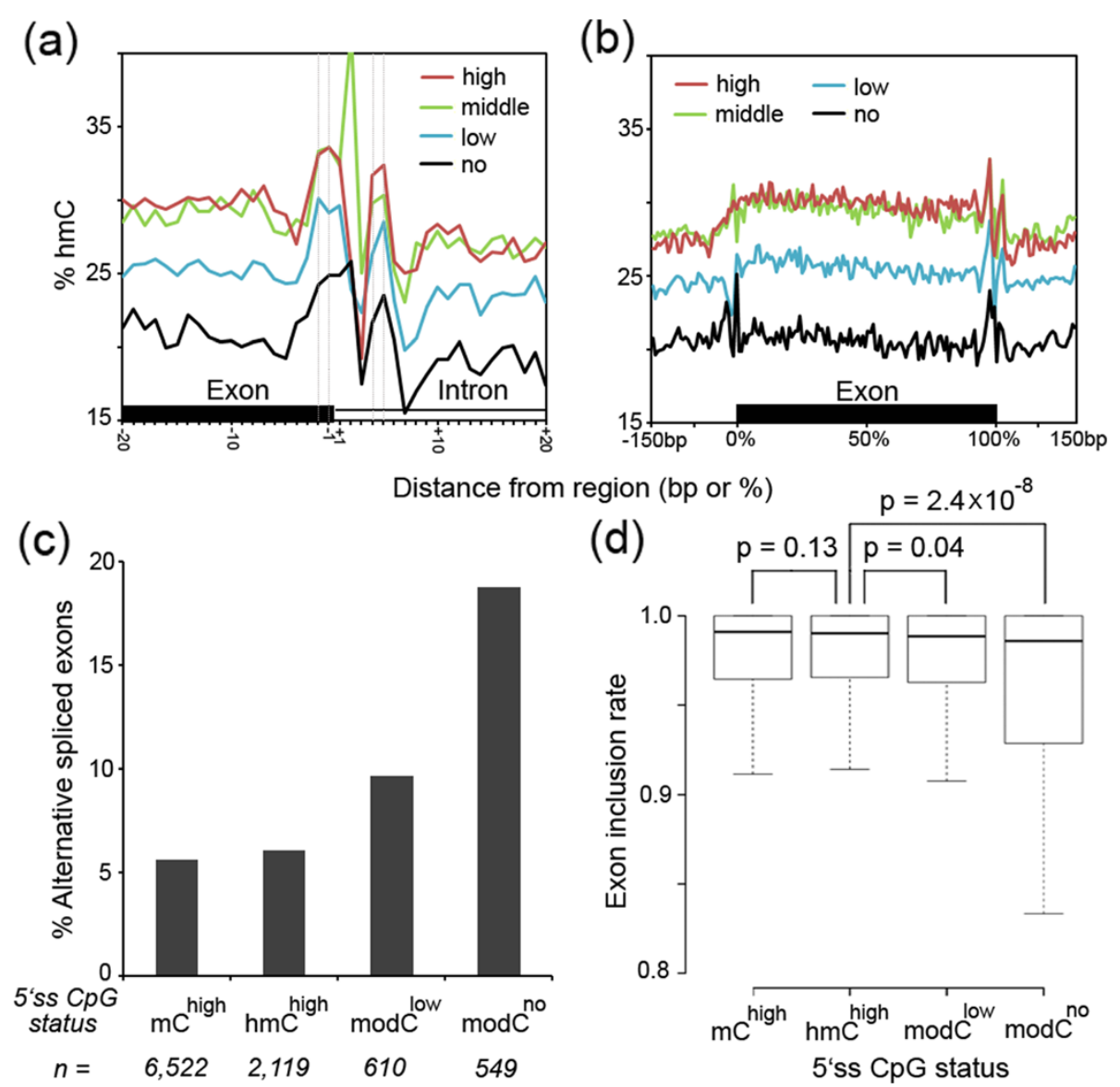

Figure 4 Correlation of the $\mathrm{hmC}$ and $\mathrm{mC}$ changes at the exon-intron boundary with gene expression and splicing. $(\mathrm{a}, \mathrm{b}) \mathrm{The} \mathrm{hmC}$ changes at the exon-intron boundary (a) and across the exon (b) are similar for exons expressed at high (red), middle (green), or low (blue) levels, as well as exons with no expression (black). (c, d) The percentages of alternatively spliced exons (c) and the inclusion rates (d) of the exons with the status of the $5^{\prime}$ ss CpG site being $\mathrm{mC}^{\text {high }}$, hmC $\mathrm{Ch}^{\text {high }}$, modC ${ }^{\text {low }}$, or modC ${ }^{\text {no }}$ showing differential splicing of these exon types. Two-tailed MWW test. $n$, number of exons.

$\bmod C^{\text {low }}$ and $\bmod C^{\text {no }}$ exons were slightly but significantly reduced comparing with the $\mathrm{hmC}^{\text {high }}$ and $\mathrm{mC}^{\text {high }}$ groups $\left(\bmod C^{\text {low }}\right.$ vs. hmC $^{\text {high }}$ : median 0.9885 vs. 0.9901, $P=0.04$; $\operatorname{modC}{ }^{\text {no }}$ vs. the hmC ${ }^{\text {high }}$ : median 0.9859 vs. $0.9901, P=$ $2.45 \times 10^{-8}$, two-tailed MWW test, Figure $4 \mathrm{~d}$ ). These data suggested that complete demethylation of $\mathrm{mC}$ and $\mathrm{hmC}$ to $C$ might lead to exon skipping, which is in line with previous studies that DNA methylation facilitates exon recognition $[32,33]$.

\section{Strand-biased hmC and $\mathrm{mC}$ on the gene body}

Previous studies have reported that $\mathrm{hmC}$ is enriched on gene bodies and positively correlated with gene expression in the adult brain $[8,9,13,21,25]$. We plotted the average $\mathrm{hmC}$ and $\mathrm{mC}$ levels across the genes at high, middle, and low expression levels and the data quantitatively confirmed that $\mathrm{hmC}$ is markedly enriched on the gene body and positively correlated with gene expression levels in the human adult brain (Figure 5a, left panel). In addition, we also showed that $\mathrm{mC}$ levels are clearly negatively correlated with gene expression (Figure 5a, right panel). Surprisingly, we observed that the $\mathrm{hmC}$ and $\mathrm{mC}$ abundances are slightly but significantly different between the sense and antisense strands, with enrichment of $\mathrm{hmC}$ on the sense strand and enrichment of $\mathrm{mC}$ on the antisense strand. The differences are positively correlated with gene expression levels as highly expressed genes show the strongest biases, whereas genes that are not expressed exhibit nearly no difference (Figure $5 \mathrm{a}$ ).

To evaluate this pattern quantitatively and at a higher level of resolution, all of the expressed genes were divided into 10 equal-sized groups (approximately 1,400 genes for each group) based on their expression levels and the gene-body $\mathrm{mC}$ and $\mathrm{hmC}$ levels were calculated for each strand of the genes. The results revealed that, from the lowest to highest expressed genes, an average seven-fold increase in the $\mathrm{hmC}$ bias $(\% \mathrm{hmC}$ of the sense strand minus that of the antisense strand, from $0.09 \%$ to 


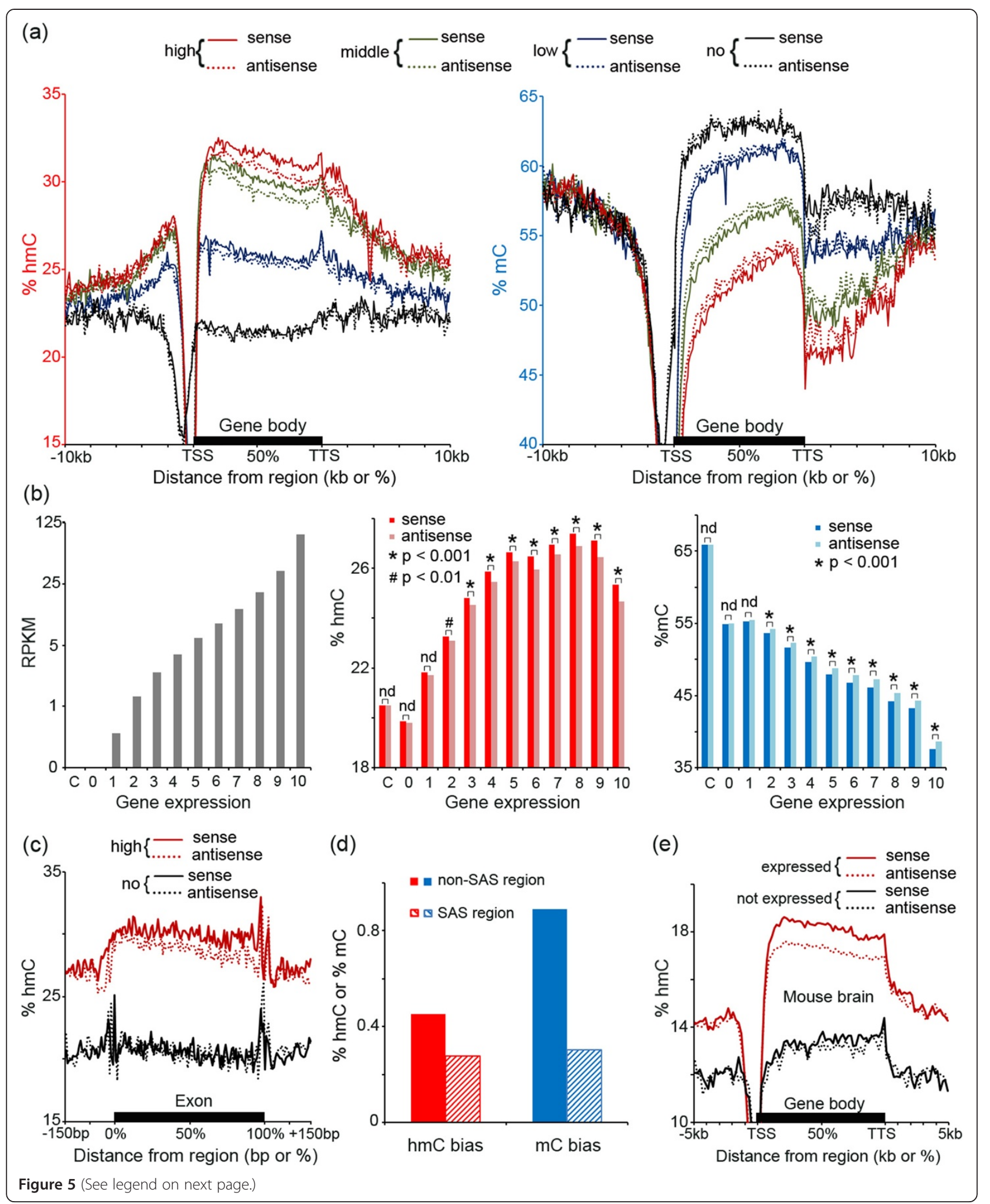


(See figure on previous page.)

Figure 5 Strand-biased $\mathrm{hmC}$ and $\mathrm{mC}$ profiles on the gene body. (a) Profiles of hmC (left panel) and $\mathrm{mC}$ (right panel) on the sense (lined) and antisense (dotted) strands of the genes expressed at high (red), middle (green) and low (blue) expression levels, as well as the genes with no expression (black). TSS and TTS indicate the transcription starting site and the transcription terminal site, respectively. (b) Expressed genes were divided into 10 groups according to the expression levels (left panel), and the average levels of $\mathrm{hmC}$ (middle panel) and $\mathrm{mC}$ (right panel) for each strand of the gene body were measured. The values for the genes that are not expressed (expression level 0 ) and randomly selected intergenic regions as the control $(C)$ are also shown. One-tailed paired Student's $t$ test. nd, no statistical difference $(P>0.05)$. (c) Profiles of hmC on the sense (lined) and antisense (dotted) strands of exons with high (red) or no (black) expression. (d) The hmC and $\mathrm{mC}$ strand-biases are reduced at the sense-antisense gene (SAS) paired regions in comparison with the non-SAS regions. (e) The hmC profile on the sense (lined) and antisense (dotted) strands of the genes that are expressed (red) or not expressed (black) in the mouse brain exhibits the transcription-correlated hmC bias toward the sense strand similar to the human pattern. The TAB-Seq, BS-Seq, and RNA-Seq data for analysis were obtained from Lister et al. [25].

$0.69 \%)$ and an average five-fold increase in the $\mathrm{mC}$ bias (\% $\mathrm{mC}$ of the antisense strand minus that of the sense strand, from $0.22 \%$ to $1.04 \%$ ) were observed (Figure $5 \mathrm{~b}$ ). Also, the strand differences of both $\mathrm{hmC}$ and $\mathrm{mC}$ are significant (for example, $P=1.63 \times 10^{-23}$ for $\mathrm{hmC}$ and $P=4.4 \times 10^{-13}$ for $\mathrm{mC}$ in genes of express group 9, twotailed and paired Student's $t$-Test, see Additional file 10 for all calculated $P$ values, as well as the $\mathrm{hmC}, \mathrm{mC}$, and modC levels on each strand of all individual genes). Both $\mathrm{hmC}$ and $\mathrm{mC}$ also displayed a slight difference in genes that are classified as not expressed $(n=8,789)$, but these differences were not statistically significant $(P=0.39$ for hmC and $P=0.44$ for $\mathrm{mC}$ ). No strand difference was found for randomly-selected intergenic regions (Figure $5 \mathrm{~b}$ ). Also, for most expression levels, the strand differences of the total modification were not significant as measured by BS-Seq (Additional file 11), explaining why it has not been observed in previous studies using BS-Seq alone.

Then we plotted the average $\mathrm{hmC}$ and $\mathrm{mC}$ levels across each strand of the exon and the results showed that the exon exhibited the strand difference at a similar level as that of the gene body, suggesting that the DNA methylation strand difference is a general feature of the transcribed exons and introns (Figure 5c and Additional file 12). To further verify the strand-bias, we analyzed the sense-antisense (SAS) gene paired regions. Since within these regions, each strand serves as both sense and antisense strands, it is expected that the strand difference should be lessened. The results indeed showed that both the $\mathrm{hmC}$ and $\mathrm{mC}$ biases decreased in the SAS regions, with a $39 \%$ reduction in the $\mathrm{hmC}$ bias $(0.45 \%$ in non-SAS region vs. $0.28 \%$ in SAS region) and a $66 \%$ reduction in the $\mathrm{mC}$ bias $(0.89 \%$ in non-SAS region $v s$. $0.3 \%$ in SAS region, Figure $5 \mathrm{~d}$ ). To generalize our observation, we analyzed the recently published TAB-Seq and BS-Seq data in the adult mouse brain [25]. The results notably showed that the mouse brain cells share a similar transcription-associated $\mathrm{hmC}$ bias toward the sense strand (Figure 5e) and an $\mathrm{mC}$ bias toward the antisense strand (Additional file 13), indicating that these $\mathrm{hmC}$ and $\mathrm{mC}$ features are evolutionary conserved between mouse and human.
To determine whether the $\mathrm{hmC}$ and $\mathrm{mC}$ strand biases are cell type-specific, we examined genes enriched in different brain cell types including neurons $(n=1,417)$, astrocytes $(n=1,807)$ and oligodendrocytes $(n=1,453)$ [34]. We found that all three gene sets and the housekeeping genes $(n=2,402)$ [35] exhibited enrichment of $\mathrm{hmC}$ on the sense strand and enrichment of $\mathrm{mC}$ on the antisense strand $(P<0.001$, Figure 6a). Furthermore, to independently validate our findings, we isolated neuronal nuclei by FACS (Figure $6 \mathrm{~b}$ and Additional file 14) and employed a Tet-assisted reduced representation bisulfite sequencing (TA-RRBS) approach by performing TAB-Seq on MspI-enriched DNA fragments of genomic DNAs extracted from these neuronal nuclei, and then quantified the hmC levels on both stands of the neuron-enriched genes. The results confirmed that $\mathrm{hmC}$ is significantly enriched on the sense strands of the neuronal genes at high expression levels (for example, $P=2.4 \times 10^{-7}$ for expression level 4 , Figure $6 \mathrm{~b}$ ). The strand difference is not significant for genes expressed at low levels $(P>0.05$ for expression levels 1 and 2, Figure 6b). Together, our data indicated a transcription-correlated $\mathrm{hmC}$ bias toward the sense strand and an $\mathrm{mC}$ bias toward the antisense strand of the gene body in both neurons and glia in the human and mouse adult brain.

\section{$\mathrm{hmC}$ is enriched at poised enhancers and is negatively correlated with repressive histone modifications}

Next, we associated the $\mathrm{hmC} / \mathrm{mC}$ profiles with the ChIP-seq data of various chromatin modification marks [27]. At the active enhancer, both $\mathrm{hmC}$ and $\mathrm{mC}$ levels are depleted towards the core region, and $\mathrm{hmC}$ is relatively accumulated at the flanking region. At the poised enhancer, both modifications revealed less pronounced reduction at the core region, particularly for $\mathrm{hmC}$ (Figure 7a). The difference in hmC profiles between the active and poised enhancers is more strikingly displayed by the high proportion of the $\mathrm{hmC}^{\text {high }}$ subgroup at the core region of the poised enhancer (Additional file 15). These results are consistent with previous reports in ESCs $[15,17]$ and in the mouse brain [25], suggesting that $\mathrm{hmC}$ 

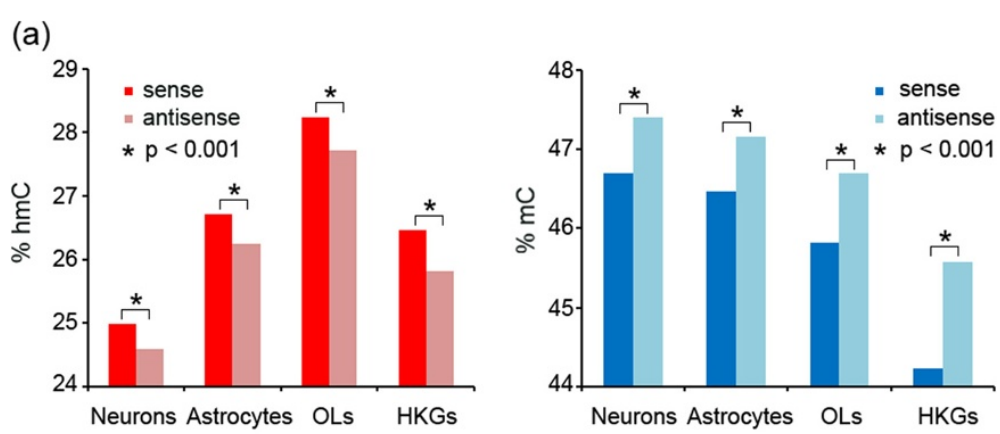

(b)

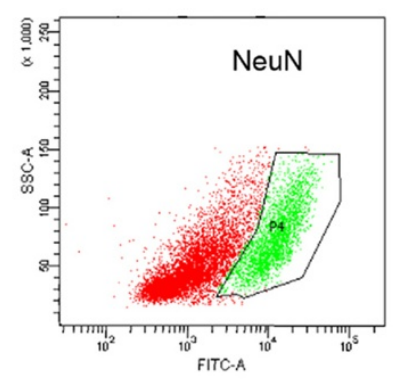

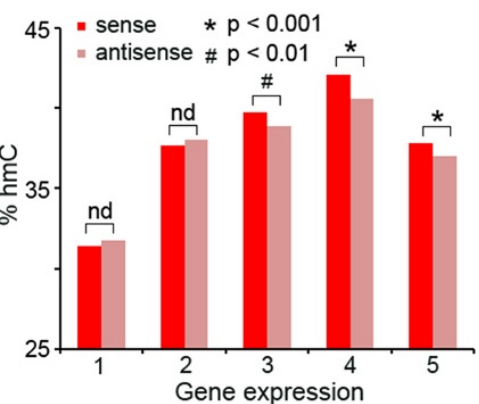

Figure 6 Strand-biased $\mathrm{hmC}$ and $\mathrm{mC}$ profiles in both neurons and glia. (a) The average levels of hmC (left panel) and $\mathrm{mC}$ (right panel) for each strand of genes enriched in different brain cell types including neurons, astrocytes and oligodendrocytes (OLs), as well as the house-keeping genes (HKGs). (b) Tet-assisted reduced representation bisulfite sequencing performed in neuron nuclei isolated by FACS using the NeuN antibody (left panel) revealed that $\mathrm{hmC}$ is significantly enriched on the sense strands of the neuronal genes expressed at high $(3,4,5)$, but not low $(1,2)$ expression levels (right panel). One-tailed paired Student's $t$ test. nd, no statistical difference $(P>0.05)$.

(a)

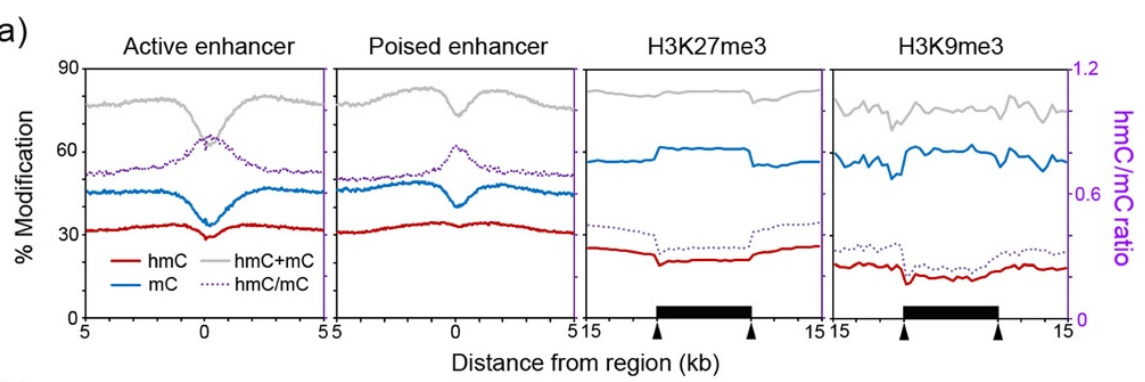

(b)

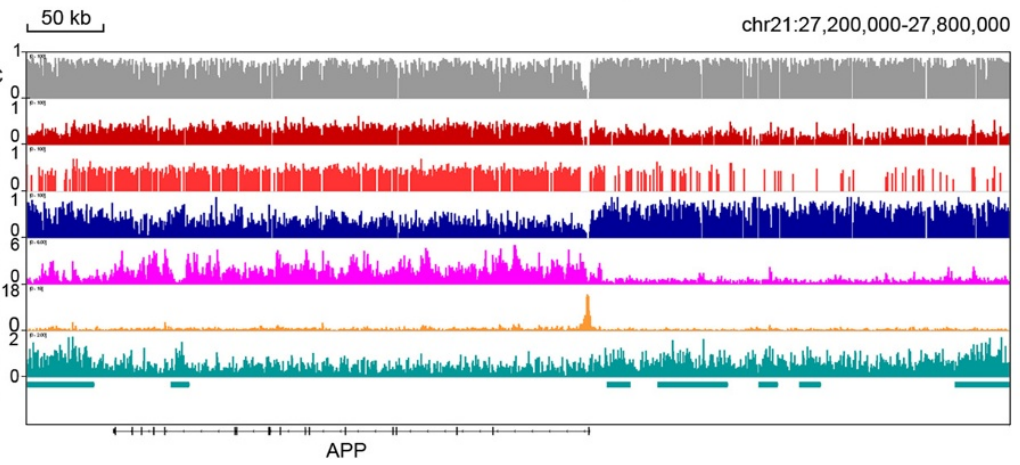

Figure $7 \mathrm{hmC} / \mathrm{mC}$ profiles on enhancers and repressive genomic regions. (a) The hmC, mC, and total DNA methylation levels, and the $\mathrm{hmC} / \mathrm{mC}$ ratios were displayed surrounding the midpoints of active or poised enhancers, or across H3K27me3- and H3K9me3-enriched regions. Arrows indicate the starting and ending points of the H3K27me3- and H3K9me3-marked regions. (b) An example of a 600-kb genomic region surrounding the APP gene showing enrichment of $\mathrm{hmC}$ and $\mathrm{H} 3 \mathrm{~K} 4 \mathrm{me} 1$ within the genic region and enrichment of $\mathrm{mC}$ and $\mathrm{H} 3 \mathrm{~K} 27 \mathrm{me} 3$ in the neighboring intergenic regions. ChIP-Seq data for H3K4me1, H3K4me3, and H3K27me3 were obtained from Zhu et al. [26]. 
also participates in maintaining a 'poised' chromatin structure of enhancers in the human adult brain.

Lastly, we address the relationship between DNA modification and two repressive histone modifications, H3K27me3 and $\mathrm{H} 3 \mathrm{~K} 9 \mathrm{me} 3$. The results demonstrated that $\mathrm{hmC}$ is clearly depleted at these repressive regions, with the average hmC levels of both the H3K27me3 and H3K9me3 regions being lower than the overall intergenic regions $(20.5 \%$ vs. $23.9 \%$ and $14.6 \%$ vs. $23.9 \%$, respectively, Figure $7 \mathrm{a}$ ). By contrast, the $\mathrm{mC}$ levels in both of these repressive regions are higher than at the overall intergenic regions (approximately $64.4 \%$ vs. $58.2 \%$, Figure $7 \mathrm{a}$ ). An example of depletion of $\mathrm{hmC}$ on the genomic regions marked by H3K27me3 and H3K9me3 was provided in Additional file 16. It was shown recently that brain tissues exist in a unique chromatin state, with expansion of H3K27me3 over a particularly large proportion of the intergenic regions, accompanied by a dramatic restriction of H3K4me1 sites within the transcriptional units [27]. The association of our $\mathrm{hmC} / \mathrm{mC}$ profiles with these two histone modification maps, as well as H3K4me3 peaks at the promoter regions, can be viewed in genomic regions surrounding the amyloid precursor protein $(A P P)$ and Neurexin 1 (NRXN1) gene loci as examples (Figure $7 \mathrm{~b}$ and Additional file 17), which are representative of transcribed genes in the adult brain.

\section{Conclusion}

In this study, we mapped DNA hydroxymethylation and methylation across the whole genome at single-base resolution in the human brain by combined application of TAB-Seq and BS-Seq, which revealed several novel insights regarding the nature of DNA methylation in brain tissues. The first intriguing finding of this study is the two striking $\mathrm{hmC}$ peaks at the $5^{\prime}$ ss, that is, the sharp increase in $\mathrm{hmC}$ levels at positions -1 and -2 at the exon side and at positions +4 and +5 at the intron side surrounding the highly conserved 'GT' splicing sequence. A previous study has revealed enrichment of DNA modification $(\mathrm{hmC}+\mathrm{mC})$ at the exon-intron boundary in human embryonic stem cells and fibroblast [30]. Since BS-Seq alone was applied in this study, $\mathrm{mC}$ and $\mathrm{hmC}$ were not distinguished. In the present study, by the combined use of TAB-Seq and BS-Seq, we unexpectedly found that it is the hmC that forms peaks at the $5^{\prime}$ ss in the adult human brain whereas $\mathrm{mC}$ is not enriched. This finding suggested that $\mathrm{hmC}$ is the key modification marking the exon-intron boundary in the adult brain tissues. It deserves to be mentioned that this pattern is evolutionary conserved since the mouse brain cells share similar hmC and $\mathrm{mC}$ features at the exon-intron boundary. A recent study also revealed significant $\mathrm{hmC}$ but not $\mathrm{mC}$ changes at the exon-intron boundary in the human and mouse brain. However, using an enzymatic method which recognized hmCs in the context of $\mathrm{C}^{\mathrm{hm}} \mathrm{CGG}$, this study only detected the intronic $\mathrm{hmC}$ decrease, while the more significantly marked hmC peaks were not reported [14]. Further studies are needed to elucidate how hmC peaks at the $5^{\prime}$ splicing sites are mechanically linked to splicing, which is under regulation by chromatin structures [36]. The results may indicate a high turnover rate of DNA methylation at the 5 'ss, or that the $\mathrm{hmC}$ specifically recruits reader proteins that directly or indirectly affect splicing. Interestingly, our analysis suggested that both $\mathrm{hmC}$ and $\mathrm{mC}$ may facilitate exon recognition. This may be related with the reports that MeCP2 (methylCpG-binding protein 2), an extremely abundant protein in brain, binds to $\mathrm{hmC}$ and $\mathrm{mC}$ with similar high affinities and helps exon recognition $[21,33]$.

Second, our data revealed a surprising transcriptioncorrelated $\mathrm{hmC}$ bias toward the sense strand and an $\mathrm{mC}$ bias toward the antisense strand of the gene body in the adult brain tissues of both human and mouse. In contrast to the well-established role of DNA methylation in CPG island promoter regions for transcription repression, the function of gene body methylation is still largely unknown [37-41]. Previous studies have revealed a positive correlation between gene expression and the gene-body $\mathrm{mC}$ level [39-42]. More recently, we and others have shown the gene-body $\mathrm{hmC}$ level is also positively correlated with gene expression in brain tissues and germ line cells $[8,9,16,21,25]$. While it has been hypothesized that the function of gene-body methylation is to repress spurious initiation of transcription within active genes including that from the repetitive elements [41,43], our finding implies to an intrinsic link between the transcription elongation and the DNA modification processes. Interestingly, an enrichment of non-CG methylation on the antisense strand has been observed in ESCs previously [29]. Regarding the establishment of this strand bias, one possibility is that the antisense strand acts as the template for mRNA transcription; the non-template strand might thus be more accessible to TET proteins in some way, resulting in the enrichment of hmCG and, hence, the accumulation of MCG and non-CG methylation on the template strand. The asymmetry distribution of DNA hydromethylation and methylation might also be interpreted in brain cells to play some regulatory roles in transcription, which should need further functional studies in the future.

Third, we demonstrated that, in the adult human brain, $13.4 \%$ of all CpGs $(n=5,692,354)$ are highlyhydroxymethylated (the $\mathrm{hmC}^{\text {high }}$ category). Since hydroxymethylation is the main modification status of these CpG sites, it points to a regulatory role of these CpG sites when hydroxymethylated. Indeed, we found that this $\mathrm{CpG}$ category is strongly enriched at enhancers and genic regions, which is distinct from the highly-methylated $\left(\mathrm{mC}^{\text {high }}\right)$, as well as the lowly-hydroxymethylated $\left(\mathrm{hmC}^{\text {low }}\right.$, 
data not shown) categories. The $\mathrm{hmC}^{\text {high }}$ is also more enriched at poised enhancers, which is distinct from enrichment of modC ${ }^{\text {low }}$ at active enhancers. Finally, we showed that the $\mathrm{hmC}$ level is greatly reduced in H3K27me3-marked regions, which is different from its enrichment on the H3K27me3-associated bivalent promoters in ESCs [5-7]. This difference should be associated with the dramatic expansion of H3K27me3 in differentiated cells and tissues including the brain [27]. It will be of interest to investigate how these highly-hydroxymethylated CpG sites might contribute to the regulation of the unique chromatin organization in the brain tissues.

In summary, we present the genome-wide and singlebase-resolution maps of $\mathrm{hmC}$ and $\mathrm{mC}$ in the human brain. The results imply novel roles for $\mathrm{hmC}$ in gene splicing and gene expression regulation. The identified highly-hydroxymethylated CpGs, which comprise $13.4 \%$ of all CpGs in human genome and are strongly enriched at poised enhancers and actively transcribed regions, also serve as a starting point for future investigations on the mechanisms that establish hydroxymethylation patterns and their associated functions in the human brain.

\section{Materials and methods}

\section{Biological samples and genomic DNA extraction}

This project was approved by the Reproductive Ethics Committee of Peking University Third Hospital (2012SZ010). Brain tissues for research were obtained with the written informed consent. The methods applied in this study are complied with the Helsinki Declaration. For TAB-Seq and BS-Seq, the adult human brain samples were obtained from a postmortem 42-year-old woman, and the fetal brain samples were obtained from an aborted 22-week-old male fetus. For LC-MS/MS, another adult human brain sample was obtained from a postmortem 28-year-old man, and another fetal sample was obtained from an aborted 22-week-old female fetus. All individuals had no sign of brain diseases. Genomic DNAs were extracted using Blood \& Cell Culture DNA Kits (Qiagen) following the manufacturer's instructions.

\section{Preparation of genomic DNA for TAB-Seq}

For TAB-Seq, genomic DNAs and spike-in control DNAs were sheared to an average size of 200 bp using a Covaris S2 instrument. Glycosylation and oxidation of genomic DNAs was performed following a previous protocol with small modifications [44]. Briefly, $5 \mu \mathrm{g}$ of sheared genomic DNA or with spike-in controls was initially glycosylated using $\beta$-glucosyltransferase proteins that were expressed and purified as previously described. Then, the DNA was purified using the QIAquick $\mathrm{Nu}-$ cleotide Removal Kit (Qiagen). Next, the oxidation reaction was performed using $1.5 \mu \mathrm{g}$ of glycosylated DNA and $30 \mu \mathrm{L}$ recombinant mTet1 protein in a $150 \mu \mathrm{L}$ reaction solution and incubated for $1 \mathrm{~h}$ at $37^{\circ} \mathrm{C}$. After proteinase $\mathrm{K}$ treatment, the oxidized DNA was first purified with Micro Bio-Spin 30 Columns (Bio-Rad) and then with $1.8 \times$ Ampure XP Beads (Beckman) following the manufacturer's suggestions.

For Tet-assisted reduced representation bisulfite sequencing (TA-RRBS), genomic DNAs extracted from purified neuron nucleus were first digested with MspI for $3 \mathrm{~h}$ at $37^{\circ} \mathrm{C}$ and purified using the QIAquick Nucleotide Removal Kit as described [45]. Then, glycosylation and oxidation of the DNA was performed similar to the TAB-Seq.

\section{Library preparation for TAB-Seq, BS-Seq, and sequencing}

The DNA sample for BS-Seq was the same batch of sheared genomic DNA with spike-in controls that was used for TAB-Seq but without glycosylation and oxidation preparation. DNA samples for TAB-Seq and BS-Seq (0.5 to $1 \mu \mathrm{g})$ were end-repaired, A-tailed, and ligated to methylated adaptors using Illumina TruSeq Sample Preparation Kits following the manufacturer's instructions. The ligated fragments were then bisulfite converted using the MethylCode Kit (Invitrogen). Bisulfite-treated DNA was separated into three reactions for PCR amplification using PfuTurbo Cx Hotstart DNA polymerase (Agilent Technologies) for seven cycles, yielding three independent libraries for the same biological sample. Final libraries were purified with $1 \times$ AMPure XP beads and sequenced using an Illumina Hiseq 2000. For Tet-assisted reduced representation bisulfite sequencing, an additional size selection of 180 to $600 \mathrm{bp}$ fragments on a $2 \%$ agarose gel was performed after the adapter ligation.

\section{Spike-in controls for TAB-Seq, TARRBS, and BS-Seq}

Fully methylated Lambda DNA was added to the human brain genomic DNAs in a ratio of 1 to 200 as a spike-in DNA control to calculate the non-conversion rates of unmodified cytosine and $\mathrm{mC}$. For the spike-in control to calculate the non-conversion rates of hmC, a DNA fragment of approximately $1.6 \mathrm{~kb}$ was amplified from a pUC19 vector using a primer pair (5'-GCAGATTG TACTGAGAGTGC-3' and $5^{\prime}$ 'TGCTGATAAATCTG GAGCCG-3') and a cocktail of dATP/dGTP/dTTP and dhmCTP (Zymo Research, Cat. No. D1045). The control was then added to genomic DNA at a ratio of 1 to 400 .

\section{RNA preparation and sequencing}

Total RNA was extracted from the tissue sample using QIAGEN RNeasy Mini Kits (Qiagen), and mRNA was isolated by Sera-Mag Oligo (dT) beads (Thermo Scientific). Libraries were prepared using the NEB Next mRNA Sample PreP Master Mix Set 1 according to the manufacturer's protocol and sequenced using an Illumina Hiseq 2000. 


\section{Quantitative analysis of $\mathrm{hmC}$ using LC-MS/MS}

Genomic DNA $(2 \mu \mathrm{g})$ was digested by nuclease P1, venom phosphodiesterase I (Type VI), and alkaline phosphatase (Sigma). After desalting and filtration, $10 \mu \mathrm{L}$ of the solution was injected into HPLC-MS/MS for analysis. HPLC-MS/ MS was carried out by reverse-phase ultra-performance liquid chromatography on an Agilent ZORBAX Eclipse XDB-C18 column (Rapid Resolution HT, $50 \times 2.1$ mm P.N. 927700-902), equipped with a ZORBAX Eclipse XDB-C8 guard column (Column: P.N. 821125-926, Cartridges P.N. 820555-901), eluted with buffer A (0.1\% formic acid in $\mathrm{H} 2 \mathrm{O})$ and buffer B (0.1\% formic acid in methanol) with a flow rate of $0.5 \mathrm{~mL}$ min- 1 at $35^{\circ} \mathrm{C}$ with a $2 \%$ to $25 \%$ gradient in $4.5 \mathrm{~min}$, with online mass spectrometry detection using Agilent 6410 triple-quadrupole (QQQ) LC mass spectrometer in multiple reaction monitoring (MRM) positive electrospray ionization (ESI) mode. The nucleosides were quantified using the nucleoside-to-base ion mass transitions of 258 to 142 with collision energy of $1 \mathrm{eV}$ $(\mathrm{hmC})$ and 228 to 112 with collision energy of $5 \mathrm{eV}(\mathrm{C})$. Quantification and detection limits were determined by comparison with the standard curves obtained from nucleoside standards running at the same volume and time.

\section{Neuronal nuclei isolation}

Nuclei extraction was processed as described [46]. Briefly, $500 \mathrm{mg}$ of cryopreserved human left frontal cortex was homogenized on ice by douncing in $5 \mathrm{~mL}$ lysis buffer (0.32 M Sucrose, $5 \mathrm{mM} \mathrm{CaCl} 2,3 \mathrm{mM}, 0.1 \mathrm{mM}$ EDTA, $10 \mathrm{mM}$ Tris- $\mathrm{HCl}$ (pH 8.0), $1 \mathrm{mM}$ DTT, and 0.1\% TritonX-100). Homogenates were transferred to ultracentrifuge tube, with Sucrose Solution (1.8 M Sucrose, $3 \mathrm{mM} \mathrm{Mg}(\mathrm{Ac}) 2,1 \mathrm{mM}$ DTT, and $10 \mathrm{mM}$ Tris- $\mathrm{HCl}$ (pH 8.0)) carefully pipetted at the bottom of the tube to form a concentration gradient. Ultracentrifugation was performed at $100,000 \mathrm{~g}$ for $2.5 \mathrm{~h}$ at $4^{\circ} \mathrm{C}$. After centrifuge, supernatant including debris was removed and the pellet was incubated in $0.5 \mathrm{~mL}$ cold PBS on ice for $20 \mathrm{~min}$ before thoroughly triturated by pipetting.

Immunostaining mix was prepared by combining $300 \mu \mathrm{L}$ PBS, $1.2 \mu \mathrm{g}$ NeuN antibody (Millipore, MAB377), $200 \mu \mathrm{L}$ Blocking Mix ( 2.5\% BSA and 10\% Goat Serum in PBS), and $2 \mu \mathrm{g}$ of Alexa Fluor 488 conjugated secondary antibody (Cell Signaling, \#4488) together and rotated for $5 \mathrm{~min}$ at room temperature in the dark. An isotype antibody control was processed in parallel by adding the same amount of mouse IgG instead of NeuN antibody. Then $1 \mathrm{~mL}$ nuclei suspension was added, and the mixture was incubated by rotating in the cold room for $45 \mathrm{~min}$. After incubation, samples were retrieved and stained with Hoechst 33342 for another $2 \mathrm{~min}$. The immunostaining result was checked under the microscope.

Immumotagged samples were diluted 10 times in PBS and filtered through a $40 \mu \mathrm{m}$ filter before loaded to the
FACS machine. A preliminary run was performed to gate out the proper nuclei size and the fluorescence bright population before the sort which separate the $\mathrm{NeuN}+$ nuclei. Once the sort was done, a small amount of sorted sample was run again through the instrument to confirm the purity.

After FACS, PBS was added to raise the volume of the sort to $10 \mathrm{~mL}$. Then the sorted sample was mixed with $2 \mathrm{~mL}$ Sucrose Solution, $50 \mu \mathrm{L} \mathrm{CaCl} 2(1 \mathrm{M})$, and $30 \mu \mathrm{L} \mathrm{Mg}$ (Ac)2 ( $1 \mathrm{M})$, and incubated on ice for $15 \mathrm{~min}$ before centrifuged at $1,786 \mathrm{~g}$ for $15 \mathrm{~min}$ at $4^{\circ} \mathrm{C}$. The $\mathrm{NeuN}+$ nuclei pellet was resuspended in PBS and went on with the Tetassisted reduced representative bisulfite sequencing.

\section{Data processing}

FASTQ format reads generated by the Illumina HiSeq2000 platform were aligned to the human reference sequence (HG19) using the Bismark program. Briefly, first, whole or any subsets of adaptor sequences were trimmed on 3 ' and $5^{\prime}$ of reads before alignment. Second, a read was removed if more than $10 \%$ bases were $\mathrm{N}$, or more than $50 \%$ bases were of Phred quality lower than 5, or at least three unmethylated CHs were present, or PCR redundancy occurred, so that only high quality data were used for downstream analysis, as described previously [17,29]. Third, cytosines in a read were computationally replaced with thymines and then mapped to computationally converted HG19 references using the Bismark program. The Lambda genome and the pUC19 sequences for the hmC spike-in control were also included in the reference sequence as extra chromosomes for assessing the non-conversion rates of unmodified cytosine, $\mathrm{mC}$, and $\mathrm{hmC}$.

\section{Assessing the non-conversion rates of unmodified} cytosine, $\mathrm{mC}$, and $\mathrm{hmC}$ and the protection rate of $\mathrm{hmC}$ The non-conversion rate of unmodified cytosine was calculated as the percentage of sequenced cytosines in non-CG contexts relative to all covered cytosines in non-CG contexts in the Lambda genome. The non-conversion rate of $\mathrm{mC}$ was calculated as the value in a CG context, and the non-conversion rate of $\mathrm{hmC}$ was measured as the value for all cytosines in the spike-in pUC19 sequences. The original data are shown in Additional file 1: Table S1. The normalized protection rate of $\mathrm{hmC}$ was assessed by dividing the non-conversion rate of $\mathrm{hmC}$ of $\mathrm{TAB}-\mathrm{Seq}$ by that of BS-Seq.

\section{Assessing the false discovery rates of $\operatorname{modC}$ and $\mathrm{hmC}$}

The $P$ value for each cytosine detected by TAB-Seq and BS-Seq was calculated via binomial distribution as previously described $[17,29]$. To measure a false discovery rate (FDR) for the modC and $\mathrm{hmC}$ sites passing a given $P$ value cutoff, we applied the Benjamini-Hochberg method [47] and set the FDR $<0.01$. The FDR was calculated separately for each chromosome and cytosine in 
each of the CG, CHG, and CHH contexts. We also applied the method described previously [17] to calculate the FDR for the TAB-Seq data and found that although this method yielded similar results for the fetal TAB-Seq data and for cytosines in the $\mathrm{CHG}$ and $\mathrm{CHH}$ contexts in the adult TAB-Seq data with a FDR $<0.05$, the FDR was higher than 0.1 even at a $P$ value of $1 \mathrm{E}-8$ when applying it to the adult TAB-Seq data. This is likely because the number of bona fide hydroxymethylated cytosines of the adult brain is much greater than those of ESCs and the fetal brain. To be consistent, we applied the BenjaminiHochberg method for both the adult and fetal TAB-Seq data. For calculating the FDR for the BS-Seq data, the Benjamini-Hochberg method yielded a similar result with the method described by Lister et al. [29].

\section{Modification frequency of individual CpG sites}

The modC frequency was calculated as dividing modCG by the total coverage according to the BS-Seq data (modCG/CG). The hmCG frequency was similarly calculated according to the TAB-Seq data (hmCG/CG), and the $\mathrm{mCG}$ frequency was calculated by subtracting hmCG/CG from modCG/CG.

\section{Quantification of the $\mathrm{hmC}$ and $\mathrm{mC}$ levels}

The $\mathrm{hmC}$ level (\%hmC) at a given genomic region or site is calculated by dividing the number of sequenced cytosines by the number of sequenced cytosines plus thymines at this region or site according to the TAB-Seq data, where the reference is in CG context. The $\mathrm{mC}$ level $(\% \mathrm{mC})$ is calculated by subtracting \% $\mathrm{hmC}$ from the total modification level $(\%(\mathrm{hmC}+\mathrm{mC}))$ according to the BS-Seq data.

\section{Genome annotation}

All genomic features were defined based on the HG19 genomic annotation downloaded from the UCSC database. Different genic elements, including transcription start sites (TSS), exons, introns, and transcription terminal sites (TTS), were defined based on the Reference Sequence (RefSeq) database. The CGIs were retrieved from the cpgIslandExt table in UCSC database, and promoter CGIs were defined as overlapping with $\pm 1 \mathrm{~kb}$ of TSS. Repetitive sequences (SINE, LINE, LTR, and Major Satellite) were acquired from the Repeat-Masker track in the UCSC database.

\section{Calculating enrichment of $\mathrm{CpG}$ categories on genomic elements}

For a given $\mathrm{CpG}$ group $\left(\bmod \mathrm{C}^{\text {low }}, \mathrm{mC}^{\text {high }}, \mathrm{hmC}^{\text {high }}\right.$, or Fetal > Adult hmCGs), we counted the fraction of the involved CpG sites at each genomic element as the 'observed' distribution value. We also counted the fraction of the overall captured genomic CpG sites at each genomic element as the 'expected' distribution value. The fold enrichment value for each genomic element was calculated by dividing the 'observed' distribution value by the 'expected' distribution value.

\section{Profiling $\mathrm{hmC}$ and $\mathrm{mC}$ at the exon-intron boundaries}

A total of 176,455 internal exons representing 18,606 genes were retrieved from the RefSeq database, with exclusion of all first last exons and single-exon genes. A total of 12,980 first exons were also retrieved. The average $\mathrm{hmC}, \mathrm{mC}$, and modC levels, the $\mathrm{hmC} / \mathrm{mC}$ ratio, the number of four modCG groups relative to all CpGs, and the CpG sites were calculated for each base \pm 150 bp around the exon-intron boundaries. The base composition was also measured $\pm 10 \mathrm{bp}$ around the $5^{\prime}$ and $3^{\prime}$ splicing sites.

\section{Calculation of exon inclusion rates}

To identify exons that are alternatively spliced, we followed the method described previously [14] with modifications. First, a library of exon-exon junction (EEJ) sequences that comprised all possible exon-exon combination for a gene was generated. Second, RNA-Seq data generated in this study were merged with RNA-Seq data of human cerebral cortex generated previously [48], and then were aligned to the EEJ library using the Bowtie program. Reads mapping to the genomic sequences were discarded before alignment. To determine an EEJ, at least eight mapped nucleotides were needed for each of the two exons. Then, the generated EEJ data were used for calculation of the inclusion value of an exon as $\%$ inclusion $=100 \times(\operatorname{sum}(\mathrm{CiA})+\operatorname{sum}(\mathrm{ACj})) /(($ sum $(\mathrm{CiA})+\operatorname{sum}(\mathrm{ACj})+2 \times(\operatorname{sum}(\mathrm{CiC} 2)+\operatorname{sum}(\mathrm{C} 1 \mathrm{Cj})))$, where $\mathrm{Ci}$ is any possible splicing donor upstream the alternative exon, $\mathrm{C} 1$ is the first splicing donor upstream the alternative exon, $\mathrm{Cj}$ is any possible splicing acceptor downstream the alternative exon, $\mathrm{C} 2$ is the first splicing acceptor downstream the alternative exon, and $\mathrm{A}$ indicates the examined exon. A minimum of 10 supporting reads are required and exons without a AG dinucleotides at the 3'splicing sites are omitted. An alternatively spliced exon was defined when the inclusion value was less than 0.8 .

\section{Strand-biased hmCG and mCG profiles on gene bodies}

Gene body regions between TSS and TTS were divided into 100 equally sized bins, and average $\mathrm{hmC}$ and $\mathrm{mC}$ levels were calculated for each bin as well as in 100-bp windows throughout $10 \mathrm{~kb}$ upstream and downstream of the gene body. The sense strand and the antisense strand were examined separately. A two-tailed and paired Student's $t$-Test was applied to determine whether the sense and antisense strand were significantly different from each other.

\section{Identification of the sense-antisense (SAS) gene paired region}

All expressed genes (RPKM $\geq 1)$ were divided into two groups according to whether they are transcribed along 
the positive strand or the negative strand. The SAS gene paired region was identified as the overlap region between these two gene groups.

\section{Identification of cell type-specific genes and house-keeping genes}

Genes enriched in different brain cell types including neurons, astrocytes, and oligodendrocytes were defined according to a previous paper with exclusion of genes that are not expressed in our RNA-Seq data [34]. The house-keeping genes were defined according a previous publication [35].

\section{Association of $\mathrm{hmC}$ and $\mathrm{mC}$ profiles with ChIP-Seq data}

To profile the distribution of $\mathrm{hmC}$ and $\mathrm{mC}$ on genomic regions with different histone modifications, we used the recently published genome-wide maps of chromatin states in the adult brain midfrontal lobe [27], including H3K4me1, H3K27ac, H3K4me3, H3K27me3, and H3K9me3.

Enhancers were defined as H3K4me1 peaks that are distant from $\pm 2.5 \mathrm{~kb}$ around any TSS in the switchDbTss table downloaded from the UCSC database. To produce the profiles in Figure 4A, we selected enhancers within intragenic regions, which account for approximately twothirds of enhancers in the adult human brain [9]. For CGI shores, we selected promoter CGIs. We checked a region $\pm 5 \mathrm{~kb}$ around the center of the H3K4me1 peak and $3 \mathrm{~kb}$ upstream and downstream of CGIs. For all profiling, the average $\mathrm{hmC}, \mathrm{mC}$, and $\operatorname{modC}$ levels, the $\mathrm{hmC} / \mathrm{mC}$ ratio, and the number of the four modCG groups $\left(\mathrm{hmC}^{\text {high }}\right.$, $\mathrm{mC}^{\text {high }}, \mathrm{mC}^{\text {all }}$, and $\operatorname{modC^{\text {low}}}$ ) relative to all CpGs were binned into 50-bp sliding windows in 25-bp steps.

To profile $\mathrm{hmC}$ and $\mathrm{mC}$ in $\mathrm{H} 3 \mathrm{~K} 27 \mathrm{me} 3-$ and H3K9me3-marked regions, each region was divided into 100 equally sized bins, and average $\mathrm{hmC}, \mathrm{mC}$, and modC levels and the $\mathrm{hmC} / \mathrm{mC}$ ratio were calculated for each bin, as well as in 1-kb windows throughout $10 \mathrm{~kb}$ upstream and downstream of the regions.

\section{Accession numbers}

The TAB-Seq and BS-Seq data have been deposited to the NCBI under accession number GSE46710, and the TA-RRBS data have been deposited under accession number GSE55249.

\section{Additional files}

Additional file 1: Table S1. Summary of sequencing details

Additional file 2: Figure S1. Quantitative values of $\mathrm{hmC}$ relative to $\mathrm{dC}$ measured by LC-MS/MS. LC-MS/MS was performed to genomic DNAs isolated from several regions of two adult brain and two fetal brain samples. For each sample, the average value with the standard deviation from technical duplicates was shown.
Additional file 3: Figure S2. Chromatograms of LC-MS/MS. The LC-MS/ MS chromatograms of hmC (left panels) and C (right panels) for genomic DNAs extracted from the adult (a) and fetal (b) frontal lobes were shown with the standard curve (c). The peak area counts are marked. Please go to the figshare website [49] for all the raw chromatograms.

Additional file 4: Figure S3. The percentages of $\mathrm{hmC}$ (by TAB-Seq) or modC (by BS-Seq) in the fetal hippocampus in the contexts of CG, CHH, and $\mathrm{CHG}$.

Additional file 5: Figure S4. Features of hydroxymethylome in the human brain. $(\mathbf{a}, \mathbf{b})$ Distribution of all covered CpGs according to their hydroxymethylation and methylation frequencies in the adult (a) and the fetal (b) brains. (c) Distribution of the CpG categories (modClow, mC $^{\text {high }}$, and $\mathrm{hmC}^{\text {high }}$ ) and all captured CpGs (All CpGs) on different genomic elements. (d) Average absolute levels of $\mathrm{hmC}$ at different genomic elements in the fetal brain.

Additional file 6: Figure S5. Prominent $\mathrm{hmC}$ changes at the exon-intron boundaries in the human brain. Profiles of hmC and mC for a 200-bp window (50 bp for exon and $150 \mathrm{bp}$ for intron) around the exon-intron and intron-exon boundaries. Modification levels of $\mathrm{hmC}, \mathrm{mC}$, total DNA methylation ( $\mathrm{hmC}+\mathrm{hmC}$ ), and the ratio of $\mathrm{hmC}$ to $\mathrm{mC}$ are shown for all internal exons $(n=176,455)$ in the sense strand.

Additional file 7: Table S2. Information of 18,036 exons having CpG sites at 5' splicing sites.

Additional file 8: Figure S6. Profiles of $\mathrm{hmC}$ and $\mathrm{mC}$ at the exon-intron boundary of exons which have a CpG at 5 'ss position +4 or +5 . Modification levels of $\mathrm{hmC}, \mathrm{mC}$, total DNA methylation $(\mathrm{hmC}+\mathrm{hmC})$ were shown for a 40-bp window around the exon-intron boundaries at single-nucleotide resolution of two types of exons, which have a CpG at 5'ss position +4 or +5 , and are named $+4 C G$ and $+5 C G$ exons, respectively. Since a CpG at one position will lead to absence of $\mathrm{CpG}$ at the nearest neighboring position and thus no methylation value, we merged the data of the sense and the antisense strands for each type of exons.

Additional file 9: Table S3. All expressed genes in the adult human brain revealed by RNA-Seq.

Additional file 10: Table S4. $\mathrm{hmC}, \mathrm{mC}$, and modC levels on each strand of all individual genes.

Additional file 11: Figure S7. The average levels of modC on sense and antisense strands of genes expressed at different levels in the adult brain. One-tailed paired Student's $t$ test. nd, no statistical difference $(P>0.01)$.

Additional file 12: Figure S8. The $\mathrm{mC}$ profiles across each strand of the exon. The profile across exons of sense (lined) and antisense (dotted) strands of highly-expressed genes (red) and no-expression genes (black) in the adult brain showed that a transcription-correlated $\mathrm{mC}$ bias toward the antisense strand of the exon.

Additional file 13: Figure S9. The $\mathrm{mC}$ profiles across each strand of the gene body in the mouse brain. The profile across genes of the sense (lined) and antisense (dotted) strands of expressed genes ( $n=11,424$, red) and genes with no expression ( $n=5,203$, black) in the adult mouse brain showed that a transcription-correlated $\mathrm{mC}$ bias toward the antisense strand of the gene body in the mouse brain. The TAB-Seq, BS-Seq, and RNA-Seq data for analysis were obtained from Lister et al. [25].

Additional file 14: Figure S10. FACS scatter plot for the control sample for isolation of neuronal nuclei, which was processed with lgG.

Additional file 15: Figure S11. Distribution of modClow, $\mathrm{mC}^{\text {high }}$, and $\mathrm{hmC}^{\text {high }}$ surrounding the midpoints of active or poised enhancers.

Additional file 16: Figure $\mathbf{S 1 2}$. $\mathrm{hmC}$ and $\mathrm{mC}$ maps in a 2-mb genomic region on chromosome 11. This example shows depletion of $\mathrm{hmC}$ and enrichment of $\mathrm{mC}$ on the H3K9me3- and H3K27me3-marked repressive regions. ChIP-Seq data for H3K4me1, H3K4me3, H3K9me3, and H3K27me3 were obtained from Zhu et al. [26].

Additional file 17: Figure S13. $\mathrm{hmC}$ and $\mathrm{mC}$ maps in a 2.8-mb genomic region surrounding the NRXN1 gene. This example shows enrichment of $\mathrm{hmC}$ and $\mathrm{H} 3 \mathrm{~K} 4 \mathrm{me} 1$ within the genic region and enrichment of $\mathrm{mC}$ and $\mathrm{H} 3 \mathrm{~K} 27 \mathrm{me} 3$ in the neighboring intergenic regions. ChIP-Seq data for H3K4me1, H3K4me3, H3K9me3, and H3K27me3 were obtained from Zhu et al. [26]. 


\section{Competing interests}

The authors declare that they have no competing interests.

\section{Authors' contributions}

LW, JQ, CH, RuiL, and FT conceived and designed the experiments. LW, XianL, LY, RongL, CS, MY, XiaoyuL, YH, HG, XW, JX, YangyuZ, YW, and YanZ performed the experiments. LW, YT, Xiaomeng $L$, and PZ conducted the bioinformatic analyses of the data. LW, CH, JQ, and FT wrote the paper (with contributions from all of the authors). All authors have read and approved the manuscript for publication.

\section{Acknowledgments}

We thank Gary C Hon for helpful discussion. JQ and FT were supported by grants from the National Basic Research Program of China (2011CB944504, 2012CB966704, and 2011CB966303) and from the National Natural Science of China (31230047, 31322037, and 31271543).

\section{Author details}

${ }^{1}$ Biodynamic Optical Imaging Center \& Center for Reproductive Medicine, College of Life Sciences, Third Hospital, Peking University, Beijing 100871, P. R. China. ${ }^{2}$ Key Laboratory of Assisted Reproduction, Ministry of Education, Beijing 100191, P. R. China. ${ }^{3}$ Department of Neurosurgery, Peking University Third Hospital, Beijing 100191, China. ${ }^{4}$ Department of Chemistry \& Institute for Biophysical Dynamics, The University of Chicago, Chicago, IL, USA. ${ }^{5}$ Ministry of Education Key Laboratory of Cell Proliferation and Differentiation, Beijing 100871, P. R. China. ${ }^{6}$ Peking-Tsinghua Center for Life Sciences, College of Life Sciences, Peking University, Beijing 100871, P. R. China.

Received: 28 November 2013 Accepted: 4 March 2014 Published: 4 March 2014

\section{References}

1. Tahiliani M, Koh KP, Shen Y, Pastor WA, Bandukwala H, Brudno Y, Agarwal S, lyer LM, Liu DR, Aravind L, Rao A: Conversion of 5-methylcytosine to 5-hydroxymethylcytosine in mammalian DNA by MLL partner TET1. Science 2009, 324:930-935.

2. Kriaucionis S, Heintz N: The nuclear DNA base 5-hydroxymethylcytosine is present in Purkinje neurons and the brain. Science 2009, 324:929-930.

3. He YF, Li BZ, Li Z, Liu P, Wang Y, Tang Q, Ding J, Jia Y, Chen Z, Li L, Sun Y, Li X, Dai Q, Song CX, Zhang K, He C, Xu GL: Tet-mediated formation of 5 -carboxylcytosine and its excision by TDG in mammalian DNA. Science 2011, 333:1303-1307.

4. Ito S, Shen L, Dai Q, Wu SC, Collins LB, Swenberg JA, He C, Zhang Y: Tet proteins can convert 5-methylcytosine to 5-formylcytosine and 5-carboxylcytosine. Science 2011, 333:1300-1303.

5. Wu H, D'Alessio AC, Ito S, Wang Z, Cui K, Zhao K, Sun YE, Zhang Y: Genome-wide analysis of 5-hydroxymethylcytosine distribution reveals its dual function in transcriptional regulation in mouse embryonic stem cells. Genes Dev 2011, 25:679-684.

6. Williams K, Christensen J, Pedersen MT, Johansen JV, Cloos PA, Rappsilber J, Helin K: TET1 and hydroxymethylcytosine in transcription and DNA methylation fidelity. Nature 2011, 473:343-348.

7. Pastor WA, Pape UJ, Huang Y, Henderson HR, Lister R, Ko M, McLoughlin EM, Brudno Y, Mahapatra S, Kapranov P, Tahiliani M, Daley GQ, Liu XS, Ecker JR, Milos PM, Agarwal S, Rao A: Genome-wide mapping of 5hydroxymethylcytosine in embryonic stem cells. Nature 2011, 473:394-397.

8. Song CX, Szulwach KE, Fu Y, Dai Q, Yi C, Li X, Li Y, Chen CH, Zhang W, Jian X, Wang J, Zhang L, Looney TJ, Zhang B, Godley LA, Hicks LM, Lahn BT, Jin $P$, He C: Selective chemical labeling reveals the genome-wide distribution of 5-hydroxymethylcytosine. Nat. Biotechnol 2011, 29:68-72.

9. Szulwach KE, Li X, Li Y, Song CX, Wu H, Dai Q, Irier H, Upadhyay AK, Gearing M, Levey Al, Vasanthakumar A, Godley LA, Chang Q, Cheng X, He C, Jin P: 5-hmC-mediated epigenetic dynamics during postnatal neurodevelopment and aging. Nat. Neurosci 2011, 14:1607-1616.

10. Ficz G, Branco MR, Seisenberger S, Santos F, Krueger F, Hore TA, Marques CJ, Andrews S, Reik W: Dynamic regulation of 5-hydroxymethylcytosine in mouse ES cells and during differentiation. Nature 2011, 473:398-402.

11. Stroud H, Feng S, Morey Kinney S, Pradhan S, Jacobsen SE: 5-Hydroxymethylcytosine is associated with enhancers and gene bodies in human embryonic stem cells. Genome Biol 2011, 12:R54.
12. Xu Y, Wu F, Tan $L$, Kong $L$, Xiong $L$, Deng J, Barbera AJ, Zheng $L$, Zhang $H$, Huang S, Min J, Nicholson T, Chen T, Xu G, Shi Y, Zhang K, Shi YG: Genome-wide regulation of $5 \mathrm{hmC}, 5 \mathrm{mC}$, and gene expression by Tet 1 hydroxylase in mouse embryonic stem cells. Mol. Cell 2011, 42:451-464.

13. Jin SG, Wu X, Li AX, Pfeifer GP: Genomic mapping of 5-hydroxymethylcytosine in the human brain. Nucleic Acids Res 2011, 39:5015-5024.

14. Khare T, Pai S, Koncevicius K, Pal M, Kriukiene E, Liutkeviciute Z, Irimia M, Jia P, Ptak C, Xia M, Tice R, Tochigi M, Moréra S, Nazarians A, Belsham D, Wong AH, Blencowe BJ, Wang SC, Kapranov P, Kustra R, Labrie V, Klimasauskas S, Petronis A: 5 -hmC in the brain is abundant in synaptic genes and shows differences at the exon-intron boundary. Nat Struct Mol Biol 2012, 19:1037-1043.

15. Sun Z, Terragni J, Borgaro JG, Liu Y, Yu L, Guan S, Wang H, Sun D, Cheng X, Zhu Z, Pradhan S, Zheng Y: High-resolution enzymatic mapping of genomic 5-hydroxymethylcytosine in mouse embryonic stem cells. Cell Rep 2013, 3:567-576.

16. Gan H, Wen L, Liao S, Lin X, Ma T, Liu J, Song CX, Wang M, He C, Han C, Tang F: Dynamics of 5-hydroxymethylcytosine during mouse spermatogenesis. Nat Commun 2013, 4:1995

17. Yu M, Hon GC, Szulwach KE, Song CX, Zhang L, Kim A, Li X, Dai Q, Shen Y, Park B, Min JH, Jin P, Ren B, He C: Base-resolution analysis of 5-hydroxymethylcytosine in the mammalian genome. Cell 2012, 149:1368-1380.

18. Booth MJ, Branco MR, Ficz G, Oxley D, Krueger F, Reik W, Balasubramanian S: Quantitative sequencing of 5-methylcytosine and 5-hydroxymethylcytosine at single-base resolution. Science 2012, 336:934-937.

19. Globisch D, Münzel M, Müller M, Michalakis S, Wagner M, Koch S, Brückl T, Biel M, Carell T: Tissue distribution of 5-hydroxymethylcytosine and search for active demethylation intermediates. PLOS ONE 2010, 5:e15367.

20. Guo JU, Su Y, Zhong C, Ming GL, Song H: Hydroxylation of 5-methylcytosine by TET1 promotes active DNA demethylation in the adult brain. Cell 2011, 145:423-434.

21. Mellén M, Ayata P, Dewell S, Kriaucionis S, Heintz N: MeCP2 binds to $5 \mathrm{hmC}$ enriched within active genes and accessible chromatin in the nervous system. Cell 2012, 151:1417-1430.

22. Spruijt CG, Gnerlich F, Smits AH, Pfaffeneder T, Jansen PW, Bauer C, Münzel M, Wagner M, Müller M, Khan F, Eberl HC, Mensinga A, Brinkman AB, Lephikov K, Müller U, Walter J, Boelens R, van Ingen H, Leonhardt H, Carell T, Vermeulen M: Dynamic readers for 5-(hydroxy)methylcytosine and its oxidized derivatives. Cell 2013, 152:1146-1159.

23. Zhang RR, Cui QY, Murai K, Lim YC, Smith ZD, Jin S, Ye P, Rosa L, Lee YK, Wu HP, Liu W, Xu ZM, Yang L, Ding YQ, Tang F, Meissner A, Ding C, Shi Y, $\mathrm{Xu}$ GL: et1 regulates adult hippocampal neurogenesis and cognition. Cell Stem Cell 2013, 13:237-45.

24. Rudenko A, Dawlaty MM, Seo J, Cheng AW, Meng J, Le T, Faull KF, Jaenisch $R$, Tsai LH: Tet1 is critical for neuronal activity-regulated gene expression and memory extinction. Neuron 2013, 79:1109-22.

25. Lister R, Mukamel EA, Nery JR, Urich M, Puddifoot CA, Johnson ND, Lucero J, Huang Y, Dwork AJ, Schultz MD, Yu M, Tonti-Filippini J, Heyn H, Hu S, Wu JC, Rao A, Esteller M, He C, Haghighi FG, Sejnowski TJ, Behrens MM, Ecker JR: Global epigenomic reconfiguration during mammalian brain development. Science 2013, 341:1237905.

26. Stadler MB, Murr R, Burger $L$, Ivanek R, Lienert $F$, Schöler A, van Nimwegen E, Wirbelauer C, Oakeley EJ, Gaidatzis D, Tiwari VK, Schübeler D: DNAbinding factors shape the mouse methylome at distal regulatory regions. Nature 2011, 480:490-495.

27. Zhu J, Adli M, Zou JY, Verstappen G, Coyne M, Zhang X, Durham T, Miri M, Deshpande V, De Jager PL, Bennett DA, Houmard JA, Muoio DM, Onder TT, Camahort R, Cowan CA, Meissner A, Epstein CB, Shoresh N, Bernstein BE: Genome-wide chromatin state transitions associated with developmental and environmental cues. Cell 2013, 152:642-654.

28. Creyghton MP, Cheng AW, Welstead GG, Kooistra T, Carey BW, Steine EJ, Hanna J, Lodato MA, Frampton GM, Sharp PA, Boyer LA, Young RA, Jaenisch R: Histone H3K27ac separates active from poised enhancers and predicts developmental state. Proc Natl Acad Sci U S A 2010, 107:21931-21936.

29. Lister R, Pelizzola M, Dowen RH, Hawkins RD, Hon G, Tonti-Filippini J, Nery JR, Lee L, Ye Z, Ngo QM, Edsall L, Antosiewicz-Bourget J, Stewart R, Ruotti V, Millar $\mathrm{AH}$, Thomson JA, Ren B, Ecker JR: Human DNA methylomes at base resolution show widespread epigenomic differences. Nature 2009, 462:315-322.

30. Laurent L, Wong E, Li G, Huynh T, Tsirigos A, Ong CT, Low HM, Kin Sung KW, Rigoutsos I, Loring J, Wei CL: Dynamic changes in the human methylome during differentiation. Genome Res 2009, 20:320-331. 
31. Chodavarapu RK, Feng S, Bernatavichute YV, Chen PY, Stroud H, Yu Y, Hetzel JA, Kuo F, Kim J, Cokus SJ, Casero D, Bernal M, Huijser P, Clark AT, Krämer U, Merchant SS, Zhang X, Jacobsen SE, Pellegrini M: Relationship between nucleosome positioning and DNA methylation. Nature 2010, 466:388-392.

32. Gelfman S, Cohen N, Yearim A, Ast G: DNA-methylation effect on cotranscriptional splicing is dependent on GC architecture of the exon-intron structure. Genome Res 2013, 23:789-799.

33. Maunakea AK, Chepelev I, Cui K, Zhao K: Intragenic DNA methylation modulates alternative splicing by recruiting MeCP2 to promote exon recognition. Cell Res 2013, 23:1256-1269.

34. Cahoy JD, Emery B, Kaushal A, Foo LC, Zamanian JL, Christopherson KS, Xing Y, Lubischer JL, Krieg PA, Krupenko SA, Thompson WJ, Barres BA: A transcriptome database for astrocytes, neurons, and oligodendrocytes: a new resource for understanding brain development and function. J Neurosci 2008, 28:264-278.

35. Eisenberg E, Levanon EY: Human housekeeping genes, revisited. Trends Genet 2013, 29:569-574.

36. Braunschweig U, Gueroussov S, Plocik AM, Graveley BR, Blencowe BJ: Dynamic integration of splicing within gene regulatory pathways. Cell 2013, 152:1252-1269.

37. Hellman A, Chess A: Gene body-specific methylation on the active $X$ chromosome. Science 2007, 315:1141-1143.

38. Zhang X, Yazaki J, Sundaresan A, Cokus S, Chan SW, Chen H, Henderson IR, Shinn P, Pellegrini M, Jacobsen SE, Ecker JR: Genome-wide high-resolution mapping and functional analysis of DNA methylation in arabidopsis. Cell 2006, 126:1189-1201.

39. Zemach A, McDaniel IE, Silva P, Zilberman D: Genome-wide evolutionary analysis of eukaryotic DNA methylation. Science 2010, 328:916-919.

40. Jones PA: Functions of DNA methylation: islands, start sites, gene bodies and beyond. Nat Rev Genet 2012, 13:484-492.

41. Ball MP, Li JB, Gao Y, Lee JH, LeProust EM, Park IH, Xie B, Daley GQ, Church GM: Targeted and genome-scale strategies reveal gene-body methylation signatures in human cells. Nat Biotechnol 2009, 27:361-368.

42. Rauch TA, Wu X, Zhong X, Riggs AD, Pfeifer GP: A human B cell methylome at 100-base pair resolution. Proc Natl Acad Sci U S A 2009, 106:671-678.

43. Bird AP: Gene number, noise reduction and biological complexity. Trends Genet 1995, 11:94-100.

44. Yu M, Hon GC, Szulwach KE, Song CX, Jin P, Ren B, He C: Tet-assisted bisulfite sequencing of 5-hydroxymethylcytosine. Nat Protoc 2012, 7:2159-2170.

45. Gu H, Smith ZD, Bock C, Boyle P, Gnirke A, Meissner A: Preparation of reduced representation bisulfite sequencing libraries for genome-scale DNA methylation profiling. Nat Protoc 2011, 6:468-481.

46. Gu H, Smith ZD, Bock C, Boyle P, Gnirke A, Meissner A: Isolation of neuronal chromatin from brain tissue. BMC Neurosci 2008, 9:42.

47. Benjamini $Y$, Hochberg Y: Controlling the false discovery rate: a practical and powerful approach to multiple testing. J Roy Stat Soc B Met 1995, 57:289-300

48. Brawand D, Soumillon M, Necsulea A, Julien P, Csardi G, Harrigan P, Weier M, Liechti A, Aximu-Petri A, Kircher MM, Albert FW, Zeller U, Khaitovich P, Grützner F, Bergmann S, Nielsen R, Pääbo S, Kaessmann H: The evolution of gene expression levels in mammalian organs. Nature 2011, 478:343-348.

49. The LC-MS/MS chromatograms of hmC and C for genomic DNAs extracted from the adult and fetal brains. http://dx.doi.org/10.6084/m9. figshare.943481.

doi:10.1186/gb-2014-15-3-r49

Cite this article as: Wen et al:: Whole-genome analysis of

5-hydroxymethylcytosine and 5-methylcytosine at base resolution in the human brain. Genome Biology 2014 15:R49.

\section{Submit your next manuscript to BioMed Central and take full advantage of:}

- Convenient online submission

- Thorough peer review

- No space constraints or color figure charges

- Immediate publication on acceptance

- Inclusion in PubMed, CAS, Scopus and Google Scholar

- Research which is freely available for redistribution

Submit your manuscript at www.biomedcentral.com/submit
C Biomed Central 